OPEN ACCESS

Edited by:

Chris Albanese,

Georgetown University, United States

Reviewed by:

Manuela Antonioli,

Istituto Nazionale per le Malattie

Infettive Lazzaro Spallanzan

(IRCCS), Italy

Susana Romero-Garcia,

Universidad Nacional Autónoma de

México, Mexico

*Correspondence:

Pierre-Emmanuel Joubert pierre-emmanuel.joubert@sorbonneuniversite.fr

Specialty section: This article was submitted to Cancer Metabolism,

a section of the journal

Frontiers in Oncology

Received: 19 July 2021 Accepted: 27 September 2021 Published: 22 October 2021

Citation:

Leonardi L, Sibéril S, Alifano M, Cremer I and Joubert P-E (2021) Autophagy Modulation by Viral Infections Influences

Tumor Development.

Front. Oncol. 11:743780. doi: 10.3389/fonc.2021.743780

\section{Autophagy Modulation by Viral Infections Influences Tumor Development}

\author{
Lucas Leonardi $^{1,2}$, Sophie Sibéril ${ }^{1,2}$, Marco Alifano $^{1,3}$, Isabelle Cremer ${ }^{1,2}$ \\ and Pierre-Emmanuel Joubert ${ }^{1,2 *}$ \\ 1 Institut National de la Santé et de la Recherche Médicale (INSERM), UMRS1138, Centre de Recherche des Cordeliers, \\ Paris, France, 2 Sorbonne Université, Univ Paris, Paris, France, ${ }^{3}$ Department of Thoracic Surgery, Hospital Cochin \\ Assistance Publique Hopitaux de Paris, Paris, France
}

Autophagy is a self-degradative process important for balancing cellular homeostasis at critical times in development and/or in response to nutrient stress. This is particularly relevant in tumor model in which autophagy has been demonstrated to have an important impact on tumor behavior. In one hand, autophagy limits tumor transformation of precancerous cells in early stage, and in the other hand, it favors the survival, proliferation, metastasis, and resistance to antitumor therapies in more advanced tumors. This catabolic machinery can be induced by an important variety of extra- and intracellular stimuli. For instance, viral infection has often been associated to autophagic modulation, and the role of autophagy in virus replication differs according to the virus studied. In the context of tumor development, virus-modulated autophagy can have an important impact on tumor cells' fate. Extensive analyses have shed light on the molecular and/or functional complex mechanisms by which virus-modulated autophagy influences precancerous or tumor cell development. This review includes an overview of discoveries describing the repercussions of an autophagy perturbation during viral infections on tumor behavior.

Keywords: tumor development and progression, autophagy, viral infection, oncolytic virus, oncogenic virus, immunity, tumor resistance, tumorigenesis

\section{AUTOPHAGY}

Autophagy is a general term defining a catabolic mechanism present in all eukaryotic cells that leads to three different intracellular routes to the degradation of substrates present in the cell by the lysosome. It includes chaperone-mediated autophagy (CMA), microautophagy, and macroautophagy. CMA is the way by which cells degrade intracellular proteins by their translocation to the lysosome through the interaction of chaperone recognizing universal motif in the sequence of CMA substrate (KFERQ motif) and the lysosome protein LAMP-2A (1). Microautophagy involves a direct engulfment of cargos through the invagination of the lysosome membrane or through the direct entry of cytoplasmic materials to the multivesicular bodies of late endosomes (1). Macroautophagy, referred hereafter as autophagy, is a multistep process consisting of the formation of phagophore that elongates, engulfs targeted proteins or organelles in a doublemembrane vesicle called autophagosome, and finally fuses with lysosome (Figure 1) (2). This process is orchestrated by more than 30 autophagic proteins (Atg), organized in complex. 
Autophagic induction is modulated by two protein complexes: the ULK1/2 (unc51-like autophagy activating kinase) and the Beclin-1/PI3KC3 (class III phosphatidylinositol 3-kinase) complexes. Once activated, these complexes recruit other proteins involved in elongation and formation of autophagosomes, including the two conjugated systems comprising Atg12-Atg5-Atg16L and LC3. After completion, the mature autophagosome fuses with lysosome to form autolysosome, wherein the sequestered materials and organelles are degraded by lysosomal enzymes (Figure 1). Even if autophagy has often been considered as a non-selective mechanism, many studies highlighted an important role for autophagy in selective materials and/or organelles recycling, including mitophagy, which selectively targets damaged mitochondria to autophagosome, or xenophagy, which permits the selective degradation of pathogens and/or pathogens' elements through autophagy (2).

Since its discovery by Christian Deduve in 1963, our knowledges on autophagy and its role in physiology has greatly been increased. Autophagy acts as a quality control mechanism by degrading and recycling damaged or old proteins and organelles. Given its important role in homeostasis, it is not surprising that a defect of autophagy has been associated with various pathologies, including neurodegenerative diseases, infection susceptibility, aging, metabolic disorders, and cancer. In cancer, autophagy seems acting as a double-edged sword: in one hand, autophagy limits the tumorigenesis of precancerous cells, and in another hand, it serves as an important survival mechanism for established tumors. The role of autophagy in cancer will be detailed in the different parts of this review and is illustrated in Figure 2.

\section{AUTOPHAGY AND VIRUSES}

As an intracellular parasite, a virus's behavior is closely linked to its capacity to prevent and/or subvert cellular antiviral responses. Given that viral infection and replication cause cellular stresses,

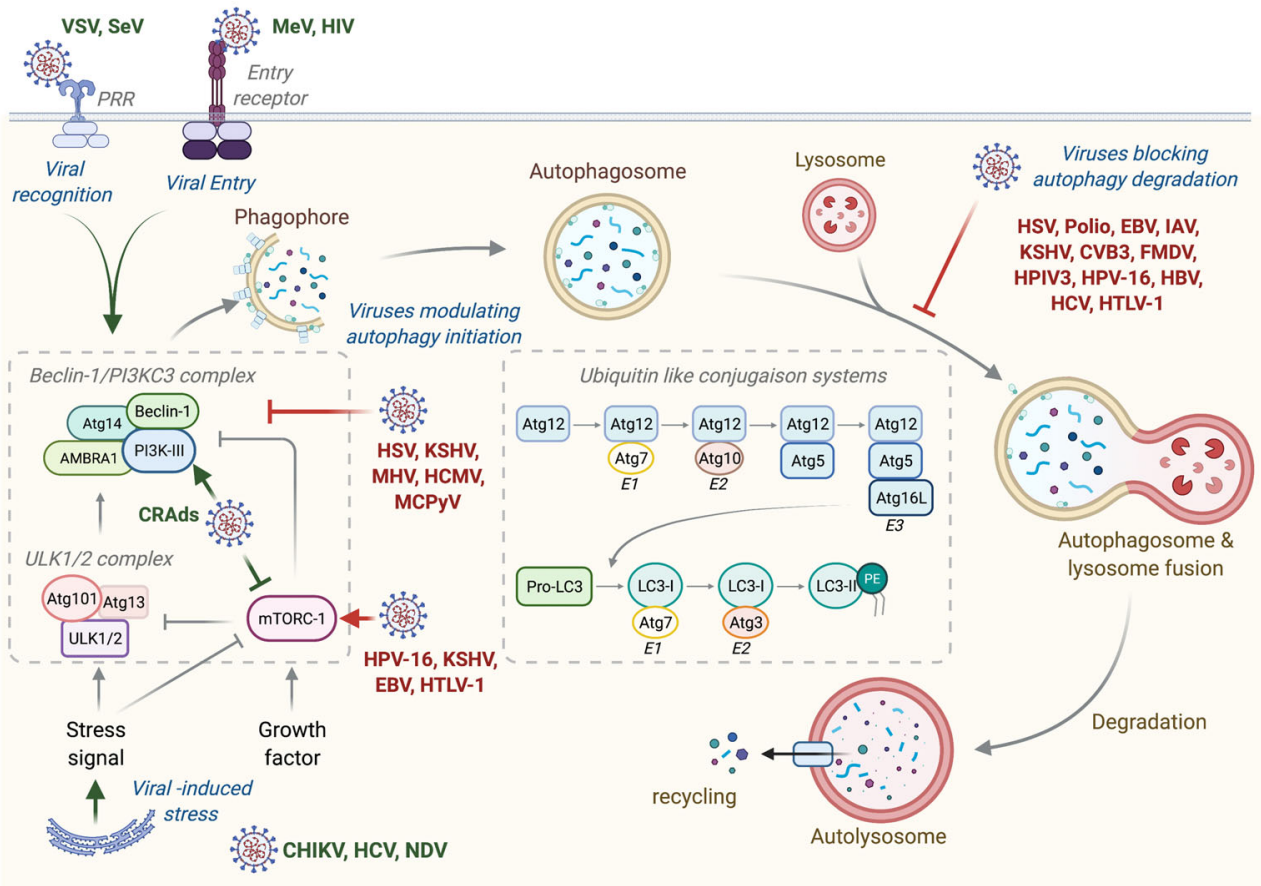

FIGURE 1 | Autophagy machinery and its modulation by viruses. Beclin-1/PI3KC3 complex activation, which is regulated by different mechanisms including the ULK1/2 complex and mTORC1 complex, results in the induction of an autophagic vesicle, which is characterized by a double-membrane, named autophagosome. Two ubiquitin-like systems are essential for autophagosome formation. In the first, autophagy-related gene-12 (Atg12) is conjugated to Atg5, together forming a complex with Atg16L1, which decorates the outer membrane of the phagophore. Microtubule-associated protein 1 light chain-3 (LC3, also known as Atg8) constitutes the second ubiquitin-like system and conjugates phosphatidylethanolamine (PE) at the outer and inner autophagosomal membrane. Unlike the Atg12/ Atg5/Atg16L1 complex that is recycled by the protease Atg4, the LC3-PE (referred to LC3-II) remains associated with the inner membrane of autophagosome. The incorporation of phospholipid into the autophagosome membrane is essential for its elongation and regulates the membrane transport system. Autophagosome maturation is characterized by the formation of an autolysosome, the product of fusion with the lysosome. Viruses activate or inhibit autophagy at several step, as indicated on the figure. VSV, Vesical Stomatitis Virus; SeV, Sendai Virus; MeV, Measles Virus; HIV, Human Immunodeficiency Virus; CRads, Conditionally Replicating Adenoviruses; HSV, Herpes Simplex Virus; KSHV, Kaposi's Sarcoma-associated Herpesvirus; MHV, Mouse Hepatitis Virus; HCMV, Human Cytomegalovirus; MCPyV, Merkel Cell Polyomavirus; HPV-16, Human Papillomavirus 16; EBV, Epstein-Barr Virus; HTLV-1, Human T cell Leukemia/lymphoma Virus type 1; CHIKV, Chikungunya Virus; HCV, Hepatitis C Virus; NDV, Newcastle Disease Virus; Polio, Poliovirus; IAV, Influenza A Virus; CVB3, Coxsackievirus B3; FMDV, Foot and Mouth Disease Virus; HPIV3, Human Parainfluenza Virus 3; HBV, Hepatitis B Virus. 


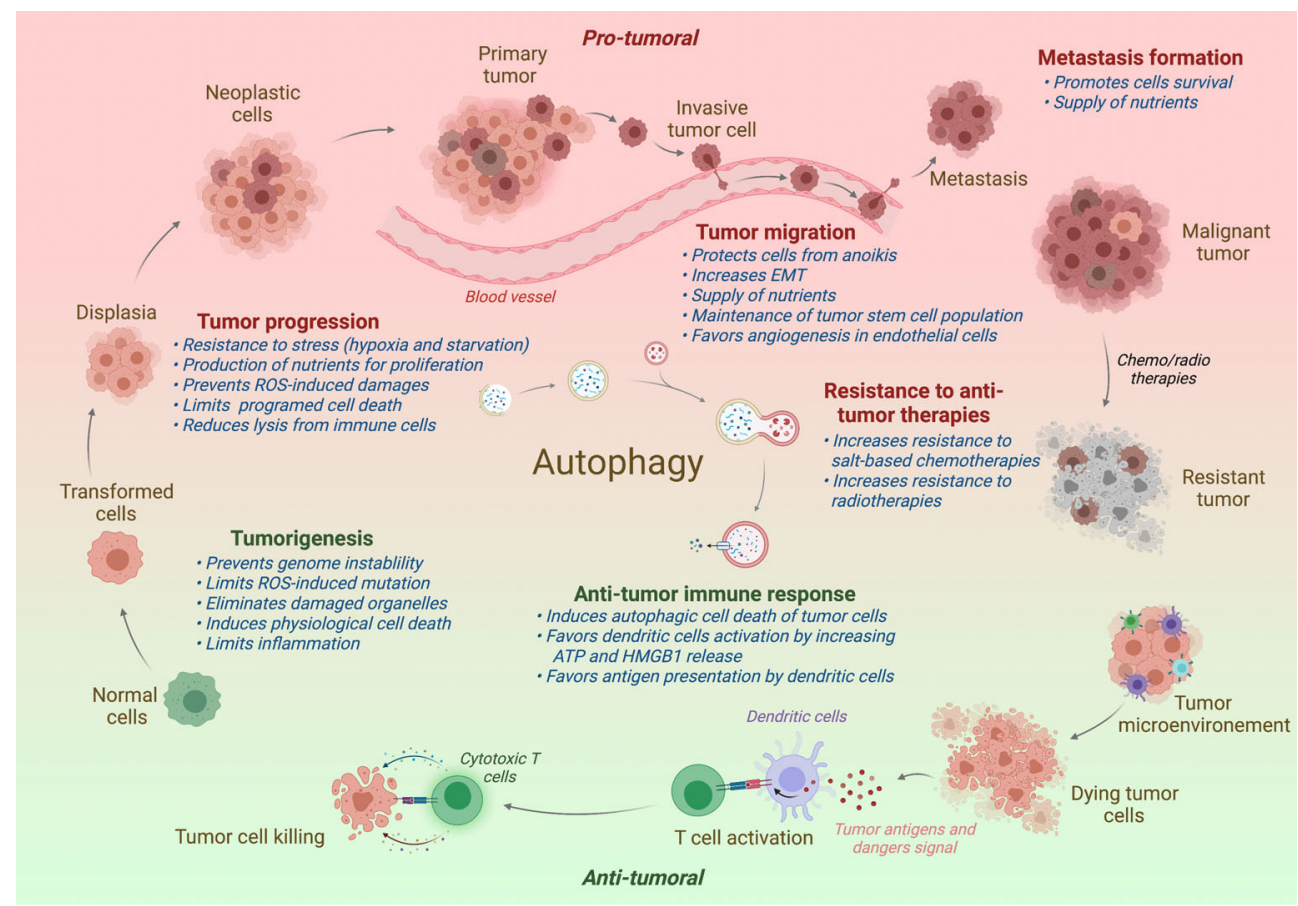

FIGURE 2 | Impact of autophagy on tumor progression. In normal cells, autophagy restricts the tumorigenesis by limiting genome instability and strong inflammation. However, when the tumor is established, autophagy has been shown to promote tumor development, including the tumor progression, migration, and the formation of metastasis. Autophagy has also been associated to a better resistance to antitumor radio- or chemotherapies. In contrast to support tumor, autophagy favors the antitumor immune responses, promoting the immunogenic cell death and the presentation of tumor antigens to the adaptive immune cells. Protumor effects of autophagy are written in red and antitumor effects in green. Effect of autophagy (blue) is indicated at different steps of tumor development. ROS, Radical oxygen species; EMT, EpithelialMesenchymal Transition.

autophagy is frequently associated with a by-product of infection. However, viral infection-induced autophagy is not a passive process, and an increasing number of studies have shown that autophagy has both antiviral and proviral capacities for the replication of a broad range of viruses (3).

\section{Viral Infections Modulate Autophagy}

Any single step of viral life cycle, including virus binding, entry and recognition, membrane fusion, exposure of viral component, and replication or even antiviral responses, may modulate autophagy (Figure 1) (4-6).

The first evidence demonstrating that virions binding could induce autophagy has been observed following measles virus $(\mathrm{MeV})$ infection (7). CD46, a complement family receptor, serves as a binding and entry receptor for vaccinal or attenuated strains of $\mathrm{MeV}(8,9)$. The team of Mathias Faure demonstrated that $\mathrm{MeV} / \mathrm{CD} 46$ binding leads to an induction of autophagy through a direct interaction of CD46 with the Beclin-1/PI3KC3 using a scaffold protein named Golgi associated PDZ and coiled coil motif-containing (GOPC) (7). Further investigations showed that $\mathrm{MeV}$ also activates autophagy by targeting an autophagyassociated protein called immunity-associated GTPase family M (IRGM) $(10,11)$. Human immunodeficiency virus type 1 (HIV1) can also activate autophagy in uninfected CD4 T cells through the fusiogenic activity of envelope glycoproteins gp120 and gp41 (called Env) (12). While specific pathway has not been really elucidated, it is important to note that the signaling activity of CD4 and CXCR4 are not associated with autophagy induction in infected cells, in contrast to the fusiogenic activity of Env proteins (12).

In addition to binding and membrane fusion, a broad range of studies have demonstrated an induction of autophagy following the virus recognition. The delivery of viral elements into the cytosol can lead to the induction of autophagy through the activation of pattern recognition receptor (PRR). Among PRR, intracellular endosomal Toll-like receptors (TLRs) are important sensors of viral components, including single-stranded (ss)RNA (e.g., TLR7 and TLR8), double-stranded (ds)RNA (e.g., TLR3), and DNA with CpG site (e.g., TLR9). The majority of TLRs recruit the adaptor myeloid differentiation primary response protein MyD88, whereas TLR3 and TLR4 recruit the TIR domain-containing adaptor molecule 1 (TRIF). In all cases, TLR stimulation leads to the activation of nuclear factor- $k B$ (NF-kB) for the production of inflammatory cytokines and interferon (IFN) production (13). TLR stimulation also activates autophagy, presumably by promoting the binding of both MyD88 or TRIF to Beclin-1 (14). The role of TLR-induced autophagy in virus remains to be determined, but several studies have shown an important impact of this process on antiviral immune responses (4). For instance, plasmacytoid dendritic cells 
(pDCs) deficient for Atg5 exhibited a reduced TLR-dependent production of IFNs after infection with vesicular stomatitis virus (VSV), sendai virus (SeV), or herpes virus type 1 (HSV-1) (15). The RIG-I like receptors (RLRs) retinoic acid-inducible gene I (RIG-I), which senses dsRNA in the cytosol, also induces autophagy following sendai virus infection (16). RIG-Imediated autophagy is regulated by the translocation of beclin1 into the mitochondria dependently of the mitochondrial antiviral signaling protein (MAVS) and tumor necrosis factor receptor-associated factor (TRAF) 6 (16). Protein Kinase R (PKR), which recognizes dsRNA, also triggers autophagy by the phosphorylation of the eukaryotic translation initiation factor (EiF) 2 (17). During HSV-1 infection, the cytosolic DNA sensor cyclic GMP_AMP (cGAMP) synthase (cGAS), which recognizes dsDNA, triggers autophagy through the activation of the initiation complex, releasing Rubicon (an autophagy inhibitor) from the beclin-1/PI3KC3 complex $(18,19)$.

Viral replication causes drastic modifications to cell homeostasis, which often enhance autophagy. As a good example, chikungunya virus (CHIKV) replication induces autophagy through the synergy of both endoplasmic reticulum (ER) and oxidative stresses (8). CHIKV proteins accumulation promotes ER stress and unfold protein responses (UPR) via the activation of inositol-requiring Ser/Thr protein kinase/ endonuclease (IRE) 1a. CHIKV also increases the production of reactive oxygen species (ROS) and reactive nitrogen species (NOS), which stimulates autophagy by activating AMP-activated protein kinase (AMPK)-mediated inhibition of mammalian target of rapamycin complex 1 (mTORC1) (20). Similar observation has been reported during HCV infection, whose replication enhances $E R$ and UPR responses that lead to autophagy induction (21).

\section{Autophagy During Viral Infection: A Double-Edged Sword}

Due to its role in cytosolic materials clearance, autophagy can degrade viral components, including viral particles or proteins or even host factors required for the replication of the virus. Indeed, autophagy is considered as an important part of innate antiviral responses, especially in non-immune cells. However, this virusspecific autophagic degradation, also known as virophagy, can be subverted by many viruses.

The first example of virophagy has been observed during Sindbis virus (SINV) infection, in which Beclin-1 and Atg5 protect against viral infection and finally against SINVmediated encephalitis (22). Mechanistically, SAMD-specific E3 ubiquitin protein ligase 1 (SMUF1) and Fanconi anemia group C protein (FANCC) are both required for the delivery of SINV capsid protein into the autophagosome, through the interaction of the autophagy receptor p62 with SINV proteins $(23,24)$. SMURF1 and FANCC are also involved in the targeting of herpes simplex virus -1 (HSV-1) proteins for autophagic degradation (24). During poliovirus infection, galectin 8 restricts viral infection through the initiation of autophagic degradation of the viral RNA genome (25). Autophagic degradation of the viral non-structural protein A5 (NS5A) of hepatitis C virus (HCV) has been observed in infected cell through the interaction of NSA5 with an ER transmembrane protein, SHISA5 (26). Human immunodeficiency virus 1 (HIV-1) replication can also be perturbed by autophagic degradation. Histone deacetylase 6 (HDAC6), in complex with the HIV restriction factor $\mathrm{APOBEC} 3 \mathrm{G}$, is responsible for the degradation of the virion infectivity factor Vif by autophagy (27). In addition to eliminate Vif factor, autophagy also selectively degrades both the transactivator Tat, involved in viral transcription, and the restriction factor tripartite motif-containing protein $5 \alpha$ (TIRM5 $\alpha$ ), respectively, in $\mathrm{HIV}$-infected $\mathrm{CD}^{+} \mathrm{T}$ cells and Langerhans cells $(28,29)$.

Autophagy can also influence the immune antiviral responses. In infected plasmacytoïd dendritic (pDC) cells, autophagy favors the transport of viral genome of vesicular stomatitis virus (VSV) from the cytosol to TLR7-containing endosome, enhancing the type I interferon (IFN) production (15). Similarly, in mouse models of murine norovirus (MNV) infection, production of IFN $\gamma$-mediated antiviral responses require the autophagy elongation complex Atg12/Atg5/ Atg16L1 (30). Importantly, the antiviral adaptive immune response can also be modulated by autophagy, mainly by promoting viral antigen presentation on class II major histocompatibility complex (MHC). That mechanism has been notably observed for Epstein-Barr virus (EBV), SINV, or HSV $(4,31)$.

While autophagy can restrict viral infection, some persisting viruses have developed several strategies to escape from the autophagic degradation, or even manipulate autophagy for their own benefit. The inhibition of autophagy induction has been noticed for a broad range of viral infections mainly by targeting Beclin-1. Indeed, HSV-encoded neurovirulence factor ICP34.5, viral homologues of Bcl-2, ORF16, or M11-respectively expressed by Kaposi's sarcoma associated herpesvirus (KHSV) and murine $\gamma$-herpers virus (MHV) $68-$ and human cytomegalovirus (HCMV)-encoded TRS1 and IRS1 are all viral proteins capable to bind Beclin-1 and inhibit autophagy (32-35). mTOR pathway, an important negative regulator of autophagy initiation complex, can also be targeted by viruses to inhibit autophagy. A good example is the KSHV G protein-coupled receptor (vGPCR), which stimulates mTOR pathway and therefore inhibits autophagy in cells during KHSV infection (36).

In addition to target the initiation step of autophagy, some viral proteins also prevent the fusion of autophagosomes with lysosomes. HSV-1 encodes the TANK-binding kinase (TBK1) protein to prevent autophagic degradation, by regulating the autophagosome maturation through the phosphorylation of the autophagy receptors p62 and optineurin (37). Similarly, the K7 protein of KHSV promotes rubicon/beclin-1 interaction and inhibits the activity of $\mathrm{PI} 3 \mathrm{KC} 3$, which leads to the blocking of the fusion of autophagosomes with lysosomes (38). In most of the cases, viruses with the ability to block autophagy maturation step can use autophagic vacuoles as support membranes for their own replication. The first example of virus that has been described to manipulate autophagy to enhance its replication is 
the poliovirus, for which autophagy inhibition decreases infection efficiency, whereas the autophagy inducer rapamycin increases it (39). Other picornaviruses, such as coxsackievirus B3 (CVB3) and foot-and-month disease virus (FMDV), also use autophagy to replicate $(40,41)$. HCV induces the formation of autophagosomes but blocks its fusion with the lysosome, which favors viral replication and virion production (42). Like K7 protein of KHSV, HCV-encoded NS4B induces rubicon expression, leading to the inhibition of autophagy maturation (43). Influenza virus (IAV) and human parainfluenza virus type 3 (HPIV3) can also trigger the accumulation of autophagosomes for viral replication, respectively, via the interaction of the viral protein M2 or M with LC3 $(44,45)$.

Indeed, manipulation of autophagy by many viruses confers double advantages for viruses: (i) it permits to avoid their degradation by inhibiting the autophagy influx, and (ii) it supplies to the viruses a double-membrane vacuole that could serve as a support for their replication.

\section{ONCOGENIC VIRUSES MODULATE AUTOPHAGY TO FAVOR TUMORIGENESIS}

\section{Oncogenic Viruses and Tumorigenesis}

Cancer is a multifactorial disease, combining genetic predispositions and environmental factors. Among all the elements promoting the cancer development, viruses can be directly linked with the formation of tumor. It is now well admitted that $15 \%$ of human cancers are caused by viruses (46). So far, only seven viruses have been demonstrated to have an oncogenic activity: Epstein-Barr virus (EBV), hepatitis $\mathrm{B}$ and $\mathrm{C}$ viruses (HBV and $\mathrm{HCV}$ ), human papilloma virus (HPV), human T lymphotrophic virus type 1 (HTLV-1), Kaposi sarcoma-associated herpes virus (KSHV), and Merkel cell polyomavirus $(\mathrm{MCPyV})$. Despite being very different in terms of tropism or viral structure and cycle, they share one characteristic: they are all responsible for persistent infections, criteria that seem to be essential to lead to virus-mediated oncogenesis. In order to persist and proliferate, viruses have to maintain their genome inside infected cell, prevent apoptosis of host cell while favoring its replication and escaping from the recognition of antiviral immune cells (47). To do that, oncogenic viruses encode proteins, called oncoproteins, that target and inactivate tumor suppressor proteins, such as retinoblastoma protein (pRb) or tumor protein 53 (p53) (48-52). p53 is a key transcription factor activated under stress responses, and it is responsible for cell cycle arrest or apoptosis induction. Similarly, $\mathrm{pRb}$ blocks cell cycle progression in G1 phase under stress conditions. HBV-encoded hepatitis B virus X (HBx), HTLV-1encoded latency-associated nuclear antigen (LANA), and $\mathrm{MCPyV}$-encoded large $\mathrm{T}$ antigen are all viral proteins that target and inhibit both p53 and pRb (52-55). Oncogenic viruses can also express proteins that target specifically p53 [such as E6 protein of HPV, latent membrane protein 1 (LMP1) of EBV, or NS5A protein of $\mathrm{HCV}$ ] or $\mathrm{pRb}$ [including core protein of $\mathrm{HCV}$, Epstein Barr virus latent 3C (EBNA3C) of EBV or E7 protein of HPV] $(56,57)$. Dysregulation of several cell cycle components, such as cyclins and cyclin dependent kinases (CDK), are also observed following oncogenic virus infection to bypass cell cycle checkpoints and pursue an infinite proliferation of infected cell. For example, E6 and E7 proteins of HPV have inhibitory activities on the CDK inhibitors p21 or p27 (58-60). Direct integration of viral genomic materials into the host genome may also modify expression of tumorigenesis-leading genes (61). Other studies demonstrated that oncogenic viruses have also developed strategy to escape from antiviral immune responses, inhibiting type I IFN response or cytotoxic activities of $\mathrm{CD}^{+} \mathrm{T}$ cells and natural killer (NK) cells (62-75).

\section{Oncogenic Viruses and Autophagy Inhibition}

In precancerous cells, autophagy limits the formation of ROS, damages of DNA, and inflammation with the consequence of limiting tumorigenesis. This observation has been established in a lot of studies using different cancer models, where a decrease of autophagy activity has been observed in precancerous cells compared with non-tumor cells. Depletion of key autophagy genes has been associated with an increase of tumorigenesis in several tissues, leading to classify some autophagy genes as tumor suppressor genes. The first autophagy gene described to be involved in tumor formation is Beclin-1, for which a monoallelic depletion has been observed in various cancers (e.g., breast, ovarian, prostate, hepatocarcinoma, or lymphoma). Depletion of UVRAG in breast, colon, gastric, and prostate cancers also increases tumorigenesis (76-79). Similarly, knockout of both conjugated systems (Atg5/Atg7 or Atg3) favors tumorigenesis in liver tumor murine model, due to the accumulation of ROS in cells (80).

An increased range of studies highlighted that oncogenic viruses are able to modulate autophagy to persist in infected cells and/or favor the virus-induced tumorigenesis [extensively reviewed elsewhere (81-83)]. For instance, HPV inhibits autophagy during several steps of viral cycle. Cellular entry of type $16 \mathrm{HPV}$ inhibits autophagy through the activation of autophagy-suppressor $\mathrm{PI} 3 \mathrm{~K} / \mathrm{akt} / \mathrm{mTOR}$ pathway, induced by the binding of viral proteins L1 and L2 to heparan sulfate proteoglycans (HSPGs) expressed on cell membrane (84). HPV-encoded E5 protein, by inhibiting p53, alters the transcription level of several autophagy genes involved in the formation of autophagosome (Beclin 1, atg5, atg7...), whereas E6 and E7 viral proteins inhibit the autophagy maturation step, observable by an accumulation of p62 $(85,86)$. In HPV-infected precancerous tissues and primary human keratinocytes, Mattoscio et al. have observed an accumulation of the autophagy receptor p62 in the cytosol of infected cells, suggesting an inhibition of autophagy in those cells (86). Similarly, in patients with oropharyngeal and oral cavity squamous cell carcinoma (SSC), HPV-positive tumors exhibit a lower level of LC3B as compared with HPV negative tumors, demonstrating that infection represses autophagy (87). Importantly, HPV-encoded E6 and E7 proteins inhibit 
autophagy maturation in anal tumor mice model, and this inhibition is associated with a greater susceptibility to HPVinduced anal carcinogenesis (88). Altogether, those studies strongly suggest that inhibition of autophagy during HPV infection actively participate in normal cells transformation.

$\mathrm{HBV}$ and HCV, the causative agents of hepatocellular carcinoma (HCC), have developed mechanisms to inhibit autophagy maturation, leading to the accumulation of autophagosomes inside infected cells and favoring the replication of viruses and the tumorigenesis (89-91). HBVencoded oncogenic protein $\mathrm{HBx}$ prevents autophagosome maturation possibly by repressing the v-ATPase activity, and therefore by impairing the fusion of autophagosome with lysosome (92). This study highlights that HBx-mediated disruption of autophagic degradation may be critical for the development of HBV-associated HCC. Importantly, downregulation of autophagy in $\mathrm{HBV}$-associated HCC patient specimens is inversely correlated with the expression of the microRNA-224 (miR-224), factor that promotes liver tumorigenesis. Moreover, the same study shows that miR-224 is preferentially recruited and degraded by autophagy, suggesting that $\mathrm{HBx}$-mediated autophagy inhibition could promote $\mathrm{HBV}$ associated tumorigenesis through the accumulation of miR-224 (93). While HBx protein has been shown to perturb the autophagic influx, another study observes an induction of $\mathrm{HBX}$-mediated autophagy in $\mathrm{HBV}$ infected cells, which promotes the degradation of tumor necrosis factor receptor superfamily member 10B (TNFS10, called also TRAIL) and prevents the TNFS10-mediated antiviral immunity (94). Moreover, HBx-mediated autophagy has also been demonstrated to play an important role in NFKB-dependent production of pro-inflammatory cytokines, such as interleukin (IL)- 6 or IL- 8 that are two predictors of HCC progression in patients suffering from chronic hepatitis infection $(95,96)$. As previously described, HCV-encoded NS4B protein induces rubicon expression, leading to the inhibition of autophagosomes maturation $(97,98)$. Autophagy inhibition leads to an accumulation of the autophagy receptor p62 in $\mathrm{HCV}$-associated HCC patients. Recent report also observed that an elevated expression of clusterin (CLU) in tumor tissues of HCV-HCC patients increases autophagy genes and upregulated p62 (99). Importantly, upregulation and phosphorylation of p62 activate the transcription factor Nrf2, involved in the metabolic reprogramming that promotes malignancy of HCV-positive HCC (100).

Viral cycles of KSHV and EBV, which belong to the herpesvirus family, are divided into two phases : a latency and a lytic phase $(101,102)$. Oncogenic properties of these viruses are linked with the latency phase, with a cell proliferation promoted and a cell survival increased. Interestingly, it has been shown that during this phase, autophagy is mainly inhibited. For KSHV infection, autophagy inhibition is led by both the viral FLICElike proteins FLIP (vFLIP) through the repression of the conjugated system LC3 and LANA viral protein by preventing the downstream autophagy genes expression related to p53 (52, $103,104)$. Autophagy is also inhibited during the lytic phase of
KHSV infection. Expression of viral G-protein-coupled receptors (vGPCR) promotes the autophagy repressor pathway PI3K/ AKT/mTOR as well as the degradation of the autophagic protein ATG14L, and viral bcl2 (vBcl2) represses Beclin-1 activation (105-107). Moreover, as previously mentioned, K7 protein of KSHV leads to the inhibition of autophagy maturation (108). The autophagy-associated protein p62 can also interfere with the lytic phase of KSHV, as an inhibition of exportin 1 (XPO1) induced retention of p62, which enhanced expression of innate immune-related genes (e.g., IRF7, ISG15, IFIT1, IFIT2, and IFIT3) that leads to a reduction of KSHV lytic replication (109). While further investigations are required to decipher the relation linking autophagy inhibition and oncogenesis in $\mathrm{KSHV}$ infected cells, one study showed that KSHV-mediated subversion of autophagy perturbs senescence and facilitates the proliferation of infected cells, two processes involved in cell tumorigenesis (110). Similarly, in EBV-infected cell, latency protein LMP-2 promotes mTOR pathway and inhibits autophagy (111). Recent study also demonstrates that EBV infection blocks the autophagic flux to favor its replication through the activation of two viral Bcl-2 homologue proteins, BHRF1 and BALF1 (112, 113). This impairment of complete autophagy leads to an accumulation of p62 in the nucleus of EBV-transformed lymphoblastic cell lines (LCLs) that promotes oxidative stress and limits the efficiency of DNA damage response, processes that could enhance virus-mediated oncogenesis (114). Recent investigation also suggested that autophagy induction, mediated by the upregulation of CXCR4 in EBV-associated gastric carcinoma (EBVaGC), protects tumor cells from apoptosis and promotes replication of EBV (115). Interestingly, publications converge to show that modulation of autophagy in EBV-infected tumor cells supports the replication of viruses and favors persistent latent infection, two processes that could facilitate tumorigenesis.

HTLV-1 also encodes an oncoprotein, called Tax-1, that modulates autophagy by acting both on autophagy initiation and maturation steps (116). In HTLV-1 transformed T or in Tax-immortalized CD4 memory $\mathrm{T}$ cells, Tax-1 facilitates autophagic initiation by activating I $\mathrm{KB}$ kinase complex, which subsequently recruits and activates the autophagy initiation complex Beclin-1/PI3KC3 (117). Tax-1 also blocks the fusion of autophagosomes with lysosomes, leading to an accumulation of autophagic vacuoles in the cytosol that promotes HTLV-1 production (118). It is interesting to note that another study has observed that HTLV-1-encoded basic leucine-zipper factor (HBZ) promotes the activity of mTOR pathway, which could be an additional autophagic suppressor mechanism in infected cells (119). These results indicate a critical role of HTLV-1deregulated autophagy in promoting survival and transformation of $\mathrm{T}$ cells infected by the virus.

$\mathrm{MCPyV}$, the causative agent of Merkel cell carcinoma (MCC), reduces autophagy level in infected cells dependently of the viral oncogenic large antigen (LT-ag) protein. LT-ag favors the expression of miR-30a-3p, miR-30a-5p, and miR-375, which target and repress the level of expression of key autophagy genes (Beclin-1, atg7, and p62) (120). In MCC tumor, low 
expression of ATG7 and p62 are correlated with MCPyVpositive tumor, suggesting the importance of autophagy evasion in $\mathrm{MCPyV}$-associated tumorigenesis. Moreover, Torin1 treatment (an mTORC1 inhibitor) induces cell death of MCC, which can be reduced by autophagy inhibitors, suggesting that $\mathrm{MCPyV}$ oncoproteins suppress autophagy to protect cancer cells from cell death (120).

\section{ONCOLYTIC VIRUSES ENHANCE AUTOPHAGY TO INCREASE TUMOR CELL DEATH AND IMMUNOGENICITY}

Oncolytic viruses (OVs) have recently emerged as a promising cancer therapeutic approach with great potential for the treatment of a broad spectrum of cancer, especially tumors that have acquired drug resistance to the first-line chemotherapeutics. OVs have been selected or designed to specifically target and kill cancer cells, with low replication capacity in normal tissues $(121,122)$. The mechanisms of tumor selectivity are multiple, including the expression of viral genome through the cancer-specific gene overexpression involved in the transcriptional element, the specific expression of virus receptor by the cancer cells, the overactivity of metabolic capacity in tumor cells (which is required for virus replication) but also tumor-specific defects of antiviral immunity [extensively reviewed elsewhere (123)]. Several interesting OVs are under investigation in preclinical and clinical studies, including coxsackievirus, adenoviruses (AdV), herpes simplex virus (HSV), Marada virus, Measles virus (MeV), Newcastle disease virus (NDV), vesicular stomatitis virus (VSV), parvovirus, and vaccinia virus (123). Direct lysis of tumor cells along with indirect induction of antitumoral immunity against specific tumor antigens are the two ways by which OVs limit tumor progression.

\section{Oncolytic Viruses and Autophagy- Dependent Cell Death}

Paradoxically, although autophagy is well recognized as a cell survival process that promotes tumor development, it can also participate in a caspase-independent form of programmed cell death. Due to the important role of autophagy in cell survival and the close relationship between autophagy and other types of cell death (e.g., apoptosis or necrosis), classification of autophagy as type of programmed cell death has been largely discussed and debated during the last decade [extensively reviewed elsewhere (124)]. However, it is now admitted that autophagy-dependent cell death $(\mathrm{ADCD})$ is a type of cell death that requires autophagy and/or autophagy components and for which the inhibition of autophagy machinery and/or components, genetically or chemically, prevents cell death (125). ADCD has been firstly described to mediate physiological cell death in vivo, during the developmental program of D. melanogaster (126), but autophagy also appears to be involved in the death of many cancer cells in response to several therapies, especially in tumors with the lack of crucial apoptotic modulators (e.g., BAX and BAK or caspases) [extensively reviewed elsewhere (127)].

Oncolytic viruses destroy tumor cells by inducing different types of cell death. For example, parvovirus and NDV exert oncolytic activities by triggering apoptotic pathways in many cancers, while vaccinia virus leads to programmed necrotic cell death in ovarian and colon infected tumor cells (128-131). In addition, some oncolytic viruses are also able to induce tumor cell lysis through autophagy induction (Figure 3) (132).

A number of different conditionally replicating adenoviruses (CRAds) have been shown to induce autophagy in tumor cells (133). In nude mice subcutaneously transfected with glioma tumor cells, adenoviruses expressing the adenovirus early (E) 1A gene (which leads to viral replication) under the control of the human telomerase reverse transcriptase promoter (hTERTAd) kill telomerase-positive tumor cells by inducing autophagic cell death, notably by inhibiting the mTORC1 activity in infected cells (134). A more recent study showed that OBP-31, an oncolytic adenovirus that is derived from hTERT-Ad, induces the autophagic cell death of human glioma tumor cells through an E2F1-mir7-EGRF pathway (135). Similarly, CRAds, which use the survivin promoter, enhance autophagy in glioma infected cells and favor the elimination of tumor cells via a beclin-1 dependent mechanism (136). Delta-24-RGD, an oncolytic adenovirus that selectively replicates in cancer cells with an abnormal $\mathrm{Rb}$ pathway, induces an autophagy-dependent cell death of brain tumor stem cells and improves the survival of glioma-bearing mice (137). In vitro experiments also showed that wild-type or E1-deficient adenoviruses induce autophagy in lung, cervical, and colon cancer cells and that autophagy induction correlates with an increase of viral replication and tumor cell death (138).

The oncolytic HSV-1 strain RH2, which lacks the $\gamma 34.5$ gene, induces the cell death of squamous cell carcinoma (SSC). While no significant changes were observed using caspase inhibitors, the cytotoxicity of $\mathrm{RH} 2$ infection was inhibited when infected tumors cells were treated with autophagy inhibitors (3methyladenine and bafilomycin), demonstrating that HSV-1/ RH2 induces autophagic cell death in SCC cells (139). In gastric carcinoma, an excessive endoplasmic reticulum stress was observed in Newcastle disease virus (NVD)-infected cancer cells, triggering autophagy and cell death (140). Similarly, Meng et al. (2012) reported that infection of malignant U251 cells with NDV boosts the formation of autophagosomes, which facilitates the replication of the virus (141). Interestingly, pharmacological modulation of autophagy was investigated in order to enhance the oncolytic potential of NDV strain FMW (NDV/FMW) in drug-resistant lung tumor cells (A549 resistant to cisplatin or paclitaxel). Combination of $\mathrm{NDV}$ with chloroquine or rapamycin significantly promoted the oncolytic efficiency of NDV/FMW in lung cancer bearing mice (142). Edmonton strain of $\mathrm{MeV}$ (MeV-Edm) exploits selective autophagy to increase its replication in non-small-cell lung cancer (NSCLC) by targeting the degradation of mitochondria via autophagy (mitophagy), which results in a decrease of innate immune response by limiting the production of RIG-I like 


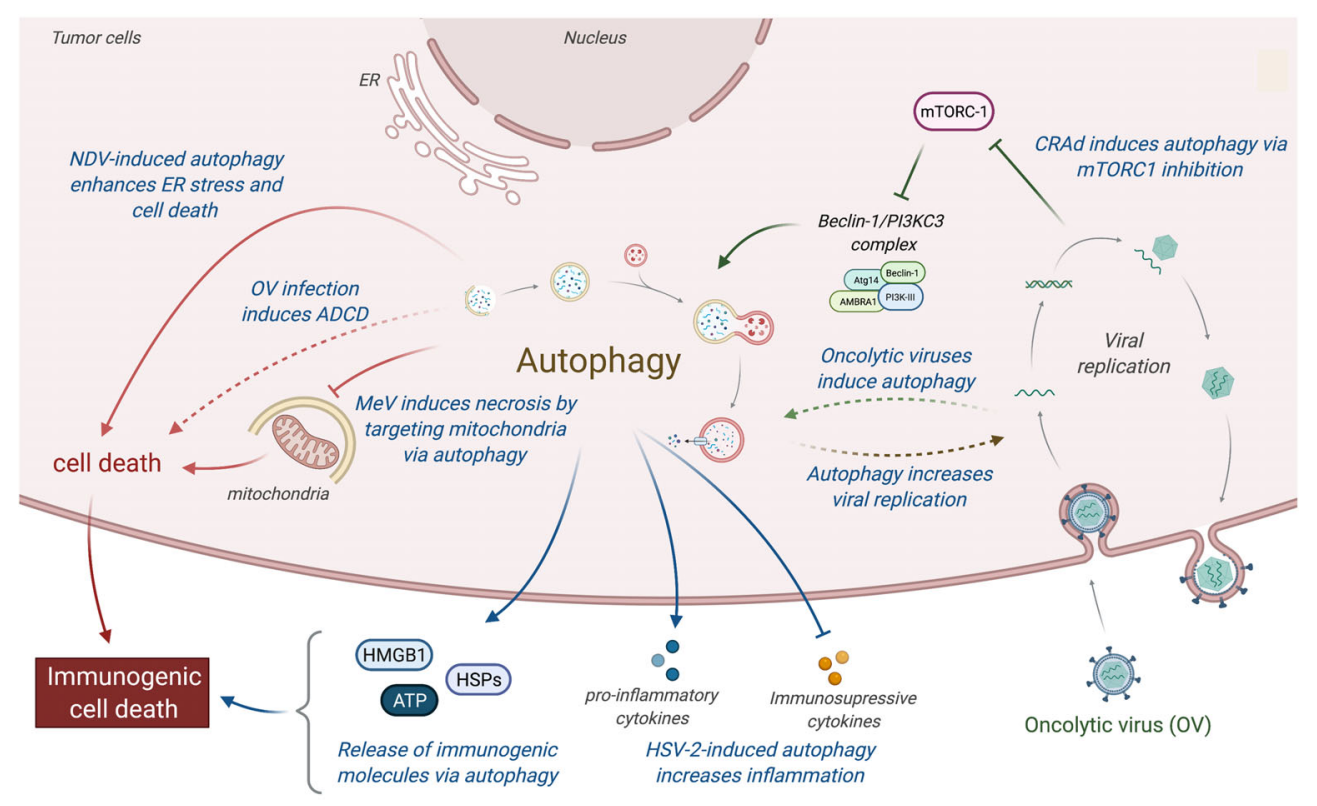

FIGURE 3 | Relations between oncolytic viruses and autophagy in tumor. Oncolytic viruses induce an immunogenic cell death by inducing autophagy, which favors the cell death of tumor-infected cells and the release of immunogenic molecules (e.g., HMGB1, ATP, or HSPs proteins). More specifically, CARds replication induces autophagy by an inhibition of mTORC1, which enhances the induction of cell death and the release of immunogenic molecules. MeV induces mitophagy to eliminate mitochondria, resulting to a decrease of apoptosis and an increase of necrosis, a more immunogenic cell death. NDV infection increases ER stress, resulting to an induction of autophagic cell death and the secretion of immunogenic molecules. In addition, HSV-2 infection can also perturb the tumor microenvironment by favoring the expression of pro-inflammatory molecules (e.g., TNF $\alpha$, IL-1 $\beta$; and GM-CSF) and limiting the production of immunosuppressive molecules (e.g., IL-10 and TGF $\beta$ ). CRads, Conditionally Replicating Adenoviruses; MeV, Measles Virus; NDV, Newcastle Disease Virus; HSV-2, Herpes Simplex Virus 2; ADCD, autophagy-dependent cell death.

receptor (RLR)-dependent type-I interferon production (143). Another study showed that the persistent viral replication mediated by $\mathrm{MeV}$-Edm-induced mitophagy prevents apoptosis but at the end leads to necrotic cell death (144), suggesting that $\mathrm{MeV}$-induced autophagy could switch from apoptosis to a more immunogenic cell death in NSCLCs following the infection.

An attractive strategy among virus-based oncolytic system is to design viral vectors that express pro-autophagic genes, in which gene-virotherapy approach significantly enhances tumor cell death by activating autophagy, especially in tumors that have acquired resistance for apoptosis. Several studies have investigated the therapeutic effect of engineered recombinant OV expressing beclin-1 gene. For example, the oncolytic adenovirus expressing beclin-1 (SG511-BECN) infection induces a significant autophagic cell death in a variety of leukemic cell lines and primary leukemic blast (145). Interestingly, SG511-BECN induces cell death of both acute and chronic myeloid leukemia, but has less cytotoxicity in normal cells. In murine leukemia model, SG511-BECN prolongs mice survival and decreases the xenograft tumor size by inducing autophagic cell death (145). Recently, oncolytic vaccinia virus that expresses Beclin-1 (OVV-BECN) was also tested for its in vitro and in vivo oncolytic activity in blood cancer (146). OVV-BECN induces a significant autophagic cell death in both wild-type leukemia and multiple myeloma cells lines and has a greater antitumor activity compared with the wild-type vaccinia virus, demonstrating a favorable therapeutic effect of autophagy in vaccinia-based treatment of blood cancers.

\section{Oncolytic Viruses and Autophagy- Mediated Immunogenic Cell Death}

Besides their direct killing potential, oncolytic viruses require the activation of immune responses to be long-lasting effective against cancer. Most of the OVs, including HSV-1, MeV, adenoviruses, or NDV, have been described to induce an immunogenic cell death (ICD), which is critical for their virotherapy efficacy (147). ICD is a type of cell death that is sufficient to induce an adaptive immune response against exogenous or endogenous antigens expressed by dying cells and elicited by the presence of danger associated molecular patterns (DAMP). While pathways of ICD induction could be multiple, it is often related to endoplasmic reticulum (ER) stress and reactive oxygen species (ROS) production (148). The main hallmarks of ICD that have been described so far include ectoexpression of calreticulin (which is normally expressed in ER), ATP release, high-mobility group box (HMGB) 1 release in 
different redox states but also the activation of annexin 1, the secretion of type I IFN and IL-1 $\beta$, or the exposure of F-actin and heat shock protein (HSP-70 and HSP90) (147). ICD leads to the activation of adaptive immune cells, including dendritic cells (DC) and T lymphocytes (LT). OVs are one of the most described ICD inducers, and infected tumor dying cells are often associated with the presence of danger signals (ATP and HMGB1 release or CRT exposure), the secretion of proinflammatory cytokines, as well as the release of tumor associated antigens (TAA), which lead to a strong activation of antitumor immune responses (149-153).

Pathways of ICD induction vary a lot between viruses, but mounting evidences indicate that autophagy plays a critical role in that induction. One of the first examples highlighting the importance of autophagy in ICD has been observed during embryonic development. During embryonic cavitation, embryonic bodies (EBs) derived from cells deficient for autophagy genes (atg5 or beclin-1) fail to cavitate. This defect is due to the persistence of cells corps during the embryonic development, which is the result of the absence of "eat-me" signal (exposure of phosphatidylserine) and the poor release of ATP in autophagy-deficient EBs (154). In tumor model, Michaud et al. reported that autophagy is required for the immunogenicity of chemotherapy-induced cell death, as autophagy-deficient dying cells fail to release ATP and subsequently to attract DC and LT into the tumor bed in colon carcinoma mice model (155). Similarly, it has been observed that radiotherapy of lung and colon cancer elicited an anticancer immune response that was dependent on autophagy-induced ATP release from dying cells, release that is required for a dense recruitment of lymphocytes into the tumor site (156). In epithelial and glioblastoma cancer cells, autophagy regulates the passive HMGB1 release from dying cells and active HMGB1 secretion $(157,158)$. Strikingly, the close correlation between autophagy induction and ICD properties observed during antitumor cytotoxic agents treatment in blood cancers supports the relationship between autophagy and ICD (158). In addition to favoring the exposition of DAMP from dying cells, autophagy can also promote antigen presentation from cancer cells to DCs and subsequently to T cells, a necessary step for the implementation of a robust antitumor immune response. Indeed, autophagy promotes the presentation of antigens not only by major histocompatibility complex (MHC) class II but also by MHC class I, as observed for endogenous viral antigens during HSV-1 infection or during influenza infection of tumor cells, and for cross-presentation of TAA from uninfected tumor cells $(159,160)$.

Oncolytic adenoviruses have been shown to induce an autophagy-dependent ICD, leading to the release of a great number of DAMP molecules and TAAs (137). In prostate cancer cells, the combination of Ad5/3 fiber-modified oncolytic adenovirus armed with granulocyte macrophage colonystimulating factor (Ad5/3-D24-GMCSF) with low-dose of temozolomide (a chemotherapeutic agent) results in the increase of intracellular level of autophagy in tumor dying cells and favors immunogenic cell death, as indicated by elevated calreticulin exposure, ATP secretion, and HMGB1 release (161).
A more recent report demonstrated that oncolytic adenovirusinduced autophagy is critical for the processing and the presentation of TAAs incorporated into viral capsid protein on MHC class II, suggesting that the combination of adenoviruses with autophagy inducers may enhance the antitumor immune responses (162). NDV infection also induces a strong ICD in lung and glioblastoma cancer cells, observable by the elevated exposure of calreticulin, the release of HMGB1, ATP, and HSP79/90, and the induction of a long-term tumor-specific immune response $(163,164)$. A recent study has shed light on the important role of autophagy in NDV-mediated ICD in lung cancer, as the depletion of autophagy-related genes, in contrast to inhibition of apoptosis or necrosis, significantly inhibits the induction of ICD determinants by NDV infection (165). In addition to increase the DAMP or TAAs expression by tumor dying cells, autophagy can also modify the tumor microenvironment. Using the herpes simplex virus type 2 (HSV-2)-based oncolytic virus $\triangle \mathrm{PK}$, one report has demonstrated that autophagy promotes the release of proinflammatory cytokines (TNF $\alpha$, IL-1 $\beta$; and GM-CSF) through the TLR2 activation, and that contributes to the inhibition of tumor immunosuppressive microenvironment in melanoma cells (166).

\section{OTHER CORRELATIONS BETWEEN VIRAL INFECTION, AUTOPHAGY, AND TUMOR PROGRESSION}

In addition to favoring the tumorigenesis and the immunogenic cell death, modulation of autophagy by viral infections could also influence other steps of tumor development, including tumor cell survival, proliferation, migration, and resistance to antitumor therapies, as well as immune response efficiency.

\section{Tumor Cell Survival}

When the tumor is established, the impact of autophagy on tumor growth and/or clinical features of patients remains unclear and seems to be greatly influenced by the type and/or the stage of the disease. However, several studies described that autophagy has pro-tumor effects, promoting the tumor cell survival, the proliferation, the migration, and the resistance to radio- and chemotherapies (Figure 2) (167). One of the most obvious involvement of autophagy in tumor growth is the fact that autophagy could recycle non-essential cytoplasmic elements to support tumor cell survival. Indeed, the more the tumor grows, the more the cells are moved away from the vascular system, leading cells under hypoxic and/or starvation condition (168). Both starvation and hypoxia have been demonstrated to induce a strong autophagy response in tumor cells, and this autophagy acts as recycling mechanism to promote stress tolerance and to supply metabolic precursors for the tumor cell survival (169, 169). Interestingly, some common oncogenic gene mutations (e.g., ras) have been shown to increase autophagy in order to maintain tumor cell survival (170). 
Autophagy could also limit the induction of programmed cell death, including apoptosis, by the selective removal of damaged organelles (e.g., damaged mitochondria) or by the selective elimination of the pro-apoptotic signal transduction [extensively reviewed elsewhere (171)]. Interestingly, several viruses have been observed to promote survival of infected cells by repressing apoptosis through an autophagy-dependent mechanism (Figure 4) (172-179). In human and mouse neuroblastoma cells, wild-type rabies virus limits apoptosis in infected cells by inducing a complete autophagic influx (179). The overexpression of $\mathrm{HBV}$ protein $\mathrm{HBx}$ and $\mathrm{HCV}$ protein NS5A can both reduce the starvation-induced cell death through the activation of autophagy and the inhibition of mitochondrial apoptosis, leading to the tumor cell survival of respectively advanced HCC and hepatoblastoma cells $(174,175)$. Similarly, the Tax protein of human T-cell leukemia virus type 1 (HTLV-1) favors the resistance of astroglioma infected cells for FASL-mediated and TRAIL-mediated apoptosis by increasing autophagy (176). In lung tumor, NDV-induced autophagy promotes viral replication and tumor cell survival by preventing cancer cells from caspases-dependent apoptosis, recruiting p62-mediated autophagy to control cytochrome c release from mitochondria (180).

Contribution of autophagy in tumor survival has also been illustrated by the fact that autophagy could prevent lysis of tumor cells from antitumor cytotoxic immune cells. For instance, autophagy has been reported to play an important role in hypoxia-induced resistance of lung tumor cells to cytolytic T lymphocyte-mediated lysis (181). Indeed, inhibition of Atg5 or Beclin-1 reduce the phosphorylation of STAT3, an important transcription factor involved in tumor survival and resistance to $\mathrm{T}$ cell cytotoxicity. Similarly, Viry et al. revealed that hypoxiainduced autophagy is responsible for the degradation of granzyme B in tumor cells delivered by NK cells, leading to their resistance to NK-mediated cell death (182). Interestingly, similar STAT3 modulation has been reported in infected cells (183). Given the fact that these proteins are also responsible for autophagy-mediated resistance to starvation in tumor, it will be very interesting to investigate the impact of virus-induced autophagy on the resistance to antitumor immunity.

\section{Metastasis Formation}

Autophagy has also been associated with metastasis formation. Actually, the role of autophagy in metastasis occurrence is controversial (184). In one hand, autophagy has been shown to limit metastasis of some tumor cells. For instance, autophagy decreases the glioblastoma tumor cells migration and invasion, reversing the epithelial-mesenchymal transition (EMT) (185). Similarly, autophagy has been associated with the selective degradation of MET/HGF receptor tyrosine kinase, two kinases

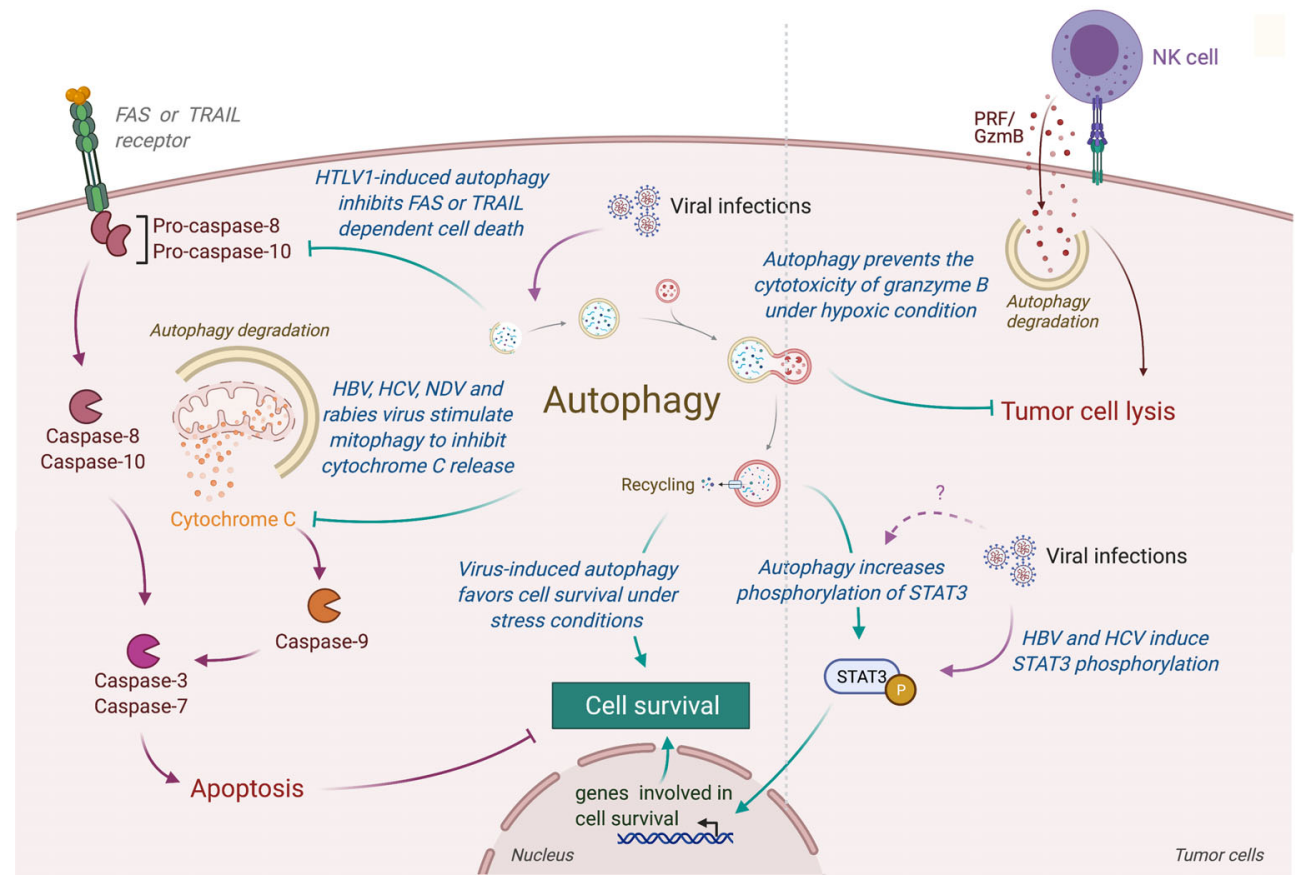

FIGURE 4 | Role of virus-induced autophagy in tumor cell survival. Viral infections can induce autophagy in tumor cells, leading to a protection of tumor cells from stress-induced or immune cells-induced cell death. In one hand, autophagy protects tumor infected cells from stress conditions (e.g., starvation or hypoxia) by limiting the accumulation of damaged organelles or by increasing the expression of genes involved in cell survival (e.g., via the phosphorylation of SATA3). In another hand, virus-induced autophagy limits the induction of apoptosis, protecting tumor cells from death receptor- or mitochondria-mediated cell death. Autophagy also takes part in the resistance of infected tumor cells from immune cell lysis by targeting and neutralizing granzyme B activity. HTLV-1, Human T cell Leukemia/lymphoma Virus type 1; HBV, Hepatitis B Virus; HCV, Hepatitis C Virus; NDV, Newcastle Disease Virus; PRF/GzmB, Perforin/Granzyme B. 
involved in cell invasion, therefore inhibiting cancer cell lines mobility (186). In the other hand, autophagy has been described to be essential for the resistance to cell-detachment-induced apoptosis, called anoikis (187). For example, the group of Jian Fan demonstrated that the inhibition of autophagy suppresses pulmonary metastasis of hepatocellular carcinoma in mice through impairing anoikis resistance (188). Emerging evidence show that autophagy not only enhances the survival of disseminating tumor cells but also promotes the survival and the maintenance of a stem-like subpopulation of tumor cells that drives invasion, treatment resistance, and cancer recurrence (189). In addition, several autophagy substrates have been shown to be involved in the regulation of the epithelialmesenchymal transition (EMT), tumor cell migration, and invasion [extensively reviewed elsewhere (190)].

Viral infections and virus-related molecules are also known to promote metastasis formation. EBV has been shown to encode several mature miRNAs, where some of them have been demonstrated to promote tumor development by targeting virus-infected host genes or self-viral genes. Several studies demonstrated that these miRNA could promote EMT, migration and metastasis of the nasopharyngeal carcinoma (NPC) cells (191-195). HPV16 E6 protein expression has been shown to increase actin polymerization through the degradation of $\mathrm{Na}+\mathrm{H}+$ exchanger regulatory factor 1 (NHERF1) protein, facilitating the migration of the cervical cancer cell and the development of metastasis (196). Viral proteins E7 of HPV16 and E1 of HCV have been shown to inactivate the tumor metastasis repressor $\mathrm{Nm} 23-\mathrm{H} 1$ in human keratinocyte $\mathrm{HaCaT}$ cell line and HCC cells line, respectively, increasing metastasis formation $(197,198)$. HSV2, HBV, or HCMV related-proteins or miRNA have also been demonstrated to promote metastasis development (199-201). Interestingly, HCMV-mediated promigratory signal requires the activation of Ras homolog family member A (RhoA), a protein involved in cell migration that can be modulated by autophagy (202). A recent report showed that under HBV infection, $\mathrm{HBx}$-induced autophagy promotes the expression of long non-coding RNA activated by transforming growth factor (TGF) $-\beta$ (lncRNA-ATB) and TGF $-\beta$, two key actors for the migration and invasion capabilities of liver cells (203).

While the role of autophagy in virus-induced metastasis needs to be further analyzed to understand the actual function of this mechanism in tumor development, it is interesting to notice the increasing number of evidences that report a strong correlation between viruses capable to modulate autophagy and their capacity to increase tumor cell migration and metastasis development.

\section{Resistance to Antitumor Therapies}

Another aspect by which autophagy favors the tumor development concern its impact on the resistance to antitumor treatments. In various tumor models (e.g., ovarian, colon, or osteosarcoma tumors), autophagy has been demonstrated to be an important actor of chemoresistance, leading to an increase of the survival of tumor cells under treatment of salt-based chemotherapies (204-208). Autophagy has also been observed to be an important promoter of resistance to radiotherapy in various tumor models, including lung, glioma, pancreatic, and colorectal cancer (209-212). Interestingly, in order to overcome this resistance, several therapeutic approaches consisting in combining chemotherapy and radiotherapy with autophagy inhibitors have emerged with very promising results $(213,214)$.

Viruses or viral proteins have also been linked with the resistance to different antitumor therapies (215-220). While mechanisms involved in viruses-mediated resistance to therapies differ with the type of viral infection, the main strategy consists in inhibiting apoptotic cell death in infected tumor cells. EBV miR BART20-5p has been observed to favor chemoresistance to 5-FU and docetaxel in gastric cancer by targeting the pro-apoptotic BCL2-associated agonist of cell death (BAD) expression (221). EBV, though the viral LMP1 protein, has been demonstrated to decrease the expression of the two pro-apoptotic factors PDCD4 and FasL, leading to a chemoresistance to cisplatin in nasopharyngeal carcinoma cells (222). EBV has also been shown to induce chemoresistance to 5$\mathrm{FU}$ in gastric cancer cells by decreasing the cleavage of PARP and caspase 3 and increasing the anti-apoptotic Bcl2 expression (223). In nasopharyngeal carcinoma, EBV-encoded miRBART4 and miR-BART8-3p favor resistance to radiotherapy by inhibiting apoptosis $(224,225)$. EBV latent viral protein LMP1 has also been demonstrated to induce radioresistance by preventing DNA Damage Response (DDR) through the phosphorylation of AMPK ( $\mathrm{thr}^{172}$ ) and inhibiting therefore its interaction with DNA-dependent protein kinase (DNA-PK), required for the DDR (226). While autophagy has not been investigated in this study, it is interesting to note that AMPK activity is an important regulator of autophagy, and AMPKinduced autophagy could help to the EBV induced radioresistance. Similarly, a recent study demonstrated that LMP1 induces autophagy via the binding of BCL2/adenovirus E1B $19 \mathrm{kDa}$ protein-interacting protein 3 (BNIP3) to beclin-1 (227). This autophagy stimulation has been shown to enhance the resistance of LMP1-positive nasopharyngeal carcinoma (NPC) cells against irradiation by protecting tumor cells from apoptosis. M. Antonioli et al. also demonstrated that HPV infection in oropharyngeal squamous cell carcinoma sensitize tumor cells to cisplatin-induced apoptosis by inhibiting autophagy, supporting the idea that modulation of autophagy during acute or latent infections could impact the resistance of tumor cells to antitumor therapies (228).

\section{Antitumor Immune Responses}

Type I interferon (IFN-I) is an important class of proinflammatory cytokines produced in response to viral infection and other environmental stresses. While IFN-I is very important for efficient virus clearance, emerging studies have shown that these proteins are also a very important driver for antitumor immunity, promoting the efficiency of immune cells to eliminate tumor [extensively reviewed elsewhere (229)]. Many intracellular pathways can recognize viral components and lead to the production of IFN-I, including the stimulation of RIG-I like receptor (RLR) and mitochondria antiviral signaling protein (MAVS), present in the outer membrane of mitochondria. 
Autophagy, notably through the targeting of mitochondria (mitophagy), is able to regulate RLR-mediated IFN-I production (230). Several viruses induce mitophagy to impair the type-I interferon production, including the SARSCoronavirus, the IAV and parainfluenza virus or $\mathrm{MeV}$ (Figure 5) (231-234). Damaged mitochondria can also release danger signals, including the reactive oxygen species (ROS) and mitochondrial DNA, which in return can activate inflammasome and the release of pro-inflammatory cytokines that could perturb tumor immunity $(235,236)$. Interestingly, some viruses, including IAV and $\mathrm{MeV}$, have been also shown to induce mitophagy to prevent NLRP3-mediated inflammation (237, 238). Autophagy could also prevent virus-induced IFN-I production by other mechanisms. Induction of autophagy by HPV16 E7 protein is responsible for the autophagic degradation of STING protein, which impairs IFN-I production and induces important deregulation of tumor immunity and promotion of Head and Neck Squamous cell carcinoma (239). Similarly, Bluetongue virus (BTV), an orbovirus targeting ruminants, impairs IFN-I pathway by preventing STAT1 phosphorylation and by degrading STAT2 through autophagy (240). Inhibition of autophagy maturation in $\mathrm{HCV}$-infected hepatocytes, through the expression of Rubicon, was recently associated with an increase of expression of type I IFN-related genes and an upregulation of HCV replication (241). Other pro-inflammatory cytokines, important for tumor immunity, could also be regulated by virus-induced autophagy. As a good example, MCMV M45 protein induces the autophagic degradation of two cellular signaling proteins involved in nuclear factor $\kappa$-light-chainenhancer of activated $\mathrm{B}$ cells $(\mathrm{NF}-\mathrm{\kappa B})$-mediated cytokine production, the NF- $\kappa \mathrm{B}$ essential modulator (NEMO), and the receptor-interacting protein kinase 1 (RIPK1) $(242,243)$.

In addition to limit pro-inflammatory cytokine production, viruses have elaborated strategies to escape from the cytotoxic immune cells. To avoid the recognition and elimination of infected cells by cytotoxic lymphocytes, many viruses decrease the major histocompatibility (MHC) class I antigen presentation pathway [extensively reviewed elsewhere (244)]. Similar strategy has also been observed in many cancer cells. The decrease of MHC-I expression has also been observed in dendritic cell (DC) infected with HIV, MCMV, or varicella zoster virus, and it has been associated with a reduction of their capacity to stimulate $\mathrm{T}$ cell proliferation (245). Interestingly, autophagy has been associated to a decrease of MHC-I expression on DC by facilitating the endocytosis and the degradation of MHC-I (246). A recent study demonstrated that autophagy regulates the expression of MHC-I in pancreatic tumor cells, as the inhibition of the autophagy machinery increased MHC-I expression on tumor cells, enhanced antitumor $\mathrm{T}$ cell response, and reduced tumor growth in mice model (247).

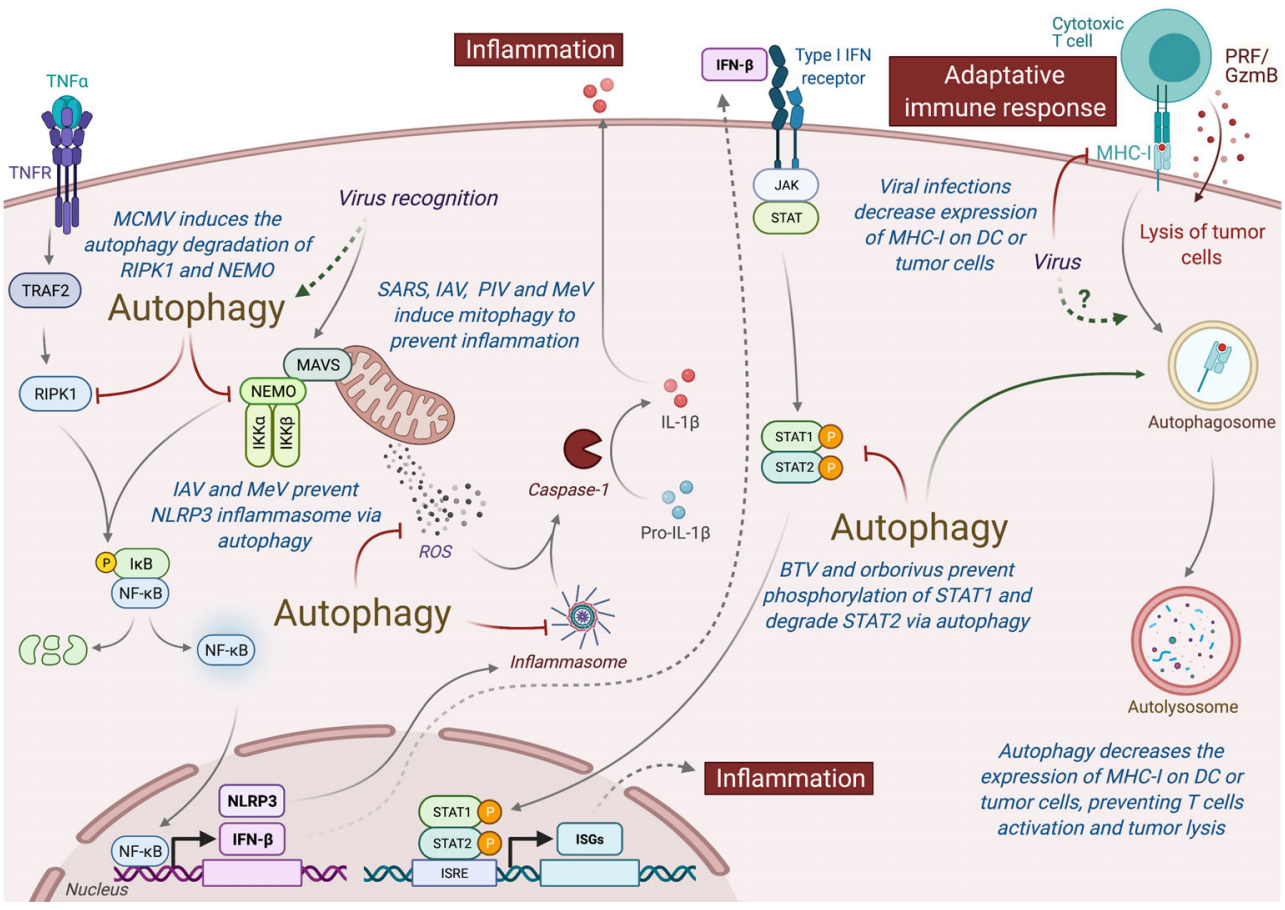

FIGURE 5 | Autophagy induced under viral infection can perturb antitumor immunity. Autophagy can interfere with innate and adaptive immunity and impact the antitumor immune responses. Viruses-induced autophagy perturbs type I IFN pathway by limiting NF-kB activation and STAT1/STAT2 phosphorylation. Several viruses (e.g., SARS, IAV, PIV, and MeV) can also modulate mitochondria activity via mitophagy and prevent inflammation by inhibiting the release of ROS or by preventing the formation of inflammasome. Viral infections or autophagy can also modulate the expression MHC-I by tumor cells or DC, limiting the action of antitumor cytotoxic T cells. MCMC, Murine Cytomegalovirus; IAV, Influenza A Virus; MeV, Measles Virus; SARS, SARS-Coronavirus; PIV, Parainfluenza Virus; BTV, Bluetongue virus; MHC-I, Major Histocompatibility Complex I; PRF/GzmB, Perforin/Granzyme B, DC, dendritic cells. 


\section{CONCLUSION}

Since several years, investigations on autophagy process shed light many biological pathways to an autophagy-dependent modulation. To understand the role of autophagy in host cells, it is important to consider the physiologic context, as autophagy could have distinct functions according to the biological model and/or the stage of the disease. During the initial step of tumor development, cells accumulate damages that disturb key molecules involved in cell cycle and promote tumorigenesis. Both tumor suppressor genes and oncogenes are implicated in autophagy regulation, linking autophagy directly to cancer occurrence. Recent discoveries showed that oncogenic viruses, which lead to the transformation of precancerous cells to malignant tumor, inhibit autophagy by targeting specifically autophagy molecules. Inhibiting autophagy in infected cells favors the accumulation of damaged organelles and/or proteins in host cells and therefore promotes the accumulation of stress components and genetic mutations.

In another hand, autophagy induced in more advanced tumor is more prone to help tumor growth. As a cellular degradative process, autophagy helps proliferative tumor cells for their nutrient supply and has an important prosurvival function, favoring tumor cell resistance to several therapies. Autophagy may also promote metastasis by protecting detached and stressed tumor cells as they travel through blood vessels and establish new colonies at distant sites. Importantly, many viruses capable to

\section{REFERENCES}

1. Tekirdag K, Cuervo AM. Chaperone-Mediated Autophagy and Endosomal Microautophagy: Joint by a Chaperone. J Biol Chem (2018) 293:5414-24. doi: $10.1074 /$ jbc.R117.818237

2. Levine B, Kroemer G. Biological Functions of Autophagy Genes: A Disease Perspective. Cell (2019) 176:11-42. doi: 10.1016/j.cell.2018.09.048

3. Mao J, Lin E, He L, Yu J, Tan P, Zhou Y. Autophagy and Viral Infection. Autophagy Regul Innate Immun (2019) 1209:55-78. doi: 10.1007/978-981-150606-2_5

4. Choi Y, Bowman J, Jung J. Autophagy During Viral Infection - A DoubleEdged Sword. Nat Rev Microbiol (2018) 16(6):341-54. doi: 10.1038/s41579018-0003-6

5. Joubert P-E, Albert ML. Autophagy During Viral Infections: A Double-Edge Sword. Virologie (2013) 17:331-42. doi: 10.1684/vir.2013.0533

6. Kudchodkar SB, Levine B. Viruses and Autophagy. Rev Med Virol (2009) 19:359-78. doi: 10.1002/rmv.630

7. Joubert P-E, Meiffren G, Grégoire IP, Pontini G, Richetta C, Flacher M, et al. Autophagy Induction by the Pathogen Receptor CD46. Cell Host Amp Microbe (2009) 6:354-66. doi: 10.1016/j.chom.2009.09.006

8. Joubert P-E, Werneke S, de la Calle C, Guivel-Benhassine F, Giodini A, Peduto L, et al. Chikungunya-Induced Cell Death Is Limited by ER and Oxidative Stress-Induced Autophagy. Autophagy (2012) 8:1261-3. doi: 10.4161/auto.20751

9. Meiffren G, Joubert P-E, Grégoire IP, Codogno P, Rabourdin-Combe C, Faure M. Pathogen Recognition by the Cell Surface Receptor CD46 Induces Autophagy. Autophagy (2010) 6:299-300. doi: 10.4161/auto.6.2.11132

10. Grégoire IP, Rabourdin-Combe C, Faure M. Autophagy and RNA Virus Interactomes Reveal IRGM as a Common Target. Autophagy (2012) 8:11367. doi: 10.4161/auto.20339

11. Rozières A, Viret C, Faure M. Autophagy in Measles Virus Infection. Viruses (2017) 9(12):359. doi: 10.3390/v9120359

12. Denizot M, Varbanov M, Espert L, Robert-Hebmann V, Sagnier S, Garcia E, et al. HIV-1 Gp41 Fusogenic Function Triggers Autophagy in Uninfected Cells. Autophagy (2008) 4:998-1008. doi: 10.4161/auto.6880 modulate autophagy have similar impact on tumor behavior, and while the direct link between autophagy and tumor development has not been well established in all studies, strong evidences have suggested an important connection between autophagy and virusmediated tumor modifications. However, further investigations are needed to clarify autophagy's modulation by viral infections and tumor development. Considering the role of autophagy in aberrant cell physiology, the understanding of these molecular processes is crucial for the development of new therapeutics against cancers and potentially other proliferative diseases.

\section{AUTHOR CONTRIBUTIONS}

LL and P-EJ performed similar bibliography. LL and P-EJ equally contributed to write the manuscript. P-EJ performed figures and supervised this work. IC, SS and MA helps authors during the conception and correction of the manuscript. All authors contributed to the article and approved the submitted version.

\section{FUNDING}

This work was supported by the "Institut National de la Sante et de la Recherche Medicale” (INSERM), Sorbonne Université and Université de Paris.

13. Lee MS, Kim Y-J. Signaling Pathways Downstream of Pattern-Recognition Receptors and Their Cross Talk. Annu Rev Biochem (2007) 76:447-80. doi: 10.1146/annurev.biochem.76.060605.122847

14. Delgado MA, Elmaoued RA, Davis AS, Kyei G, Deretic V. Toll-Like Receptors Control Autophagy. EMBO J (2008) 27:1110-21. doi: 10.1038/ emboj.2008.31

15. Lee HK, Lund JM, Ramanathan B, Mizushima N, Iwasaki A. AutophagyDependent Viral Recognition by Plasmacytoid Dendritic Cells. Science (2007) 315:1398-401. doi: 10.1126/science.1136880

16. Lee N-R, Ban J, Lee N-J, Yi C-M, Choi J-Y, Kim H, et al. Activation of RIG-IMediated Antiviral Signaling Triggers Autophagy Through the MAVSTRAF6-Beclin-1 Signaling Axis. Front Immunol (2018) 9:2096 doi: 10.3389/fimmu.2018.02096

17. Tallóczy Z, Jiang W, Virgin HW, Leib DA, Scheuner D, Kaufman RJ, et al Regulation of Starvation- and Virus-Induced Autophagy by the Eif $2 \alpha$ Kinase Signaling Pathway. Proc Natl Acad Sci USA (2002) 99:190-5. doi: 10.1073/ pnas.012485299

18. Konno H, Konno K, Barber GN. Cyclic Dinucleotides Trigger ULK1 (ATG1) Phosphorylation of STING to Prevent Sustained Innate Immune Signaling. Cell (2013) 155:688-98. doi: 10.1016/j.cell.2013.09.049

19. Liang Q, Seo GJ, Choi YJ, Kwak M-J, Ge J, Rodgers MA, et al. Crosstalk Between the Cgas DNA Sensor and Beclin-1 Autophagy Protein Shapes Innate Antimicrobial Immune Responses. Cell Host Microbe (2014) 15:22838. doi: 10.1016/j.chom.2014.01.009

20. Joubert P-E, Werneke SW, de la Calle C, Guivel-Benhassine F, Giodini A Peduto L, et al. Chikungunya Virus-Induced Autophagy Delays CaspaseDependent Cell Death. J Exp Med (2012) 209:1029-47. doi: 10.1084/ jem.20110996

21. Dash S, Chava S, Aydin Y, Chandra PK, Ferraris P, Chen W, et al. Hepatitis C Virus Infection Induces Autophagy as a Prosurvival Mechanism to Alleviate Hepatic ER-Stress Response. Viruses (2016) 8(5):150. doi: 10.3390/v8050150

22. Orvedahl A, MacPherson S, Sumpter R, Tallóczy Z, Zou Z, Levine B. Autophagy Protects Against Sindbis Virus Infection of the Central Nervous System. Cell Host Microbe (2010) 7:115-27. doi: 10.1016/ j.chom.2010.01.007 
23. Orvedahl A, Sumpter R, Xiao G, Ng A, Zou Z, Tang Y, et al. Image-Based Genome-Wide Sirna Screen Identifies Selective Autophagy Factors. Nature (2011) 480:113-7. doi: 10.1038/nature10546

24. Sumpter R, Sirasanagandla S, Fernández ÁF, Wei Y, Dong X, Franco L, et al. Fanconi Anemia Proteins Function in Mitophagy and Immunity. Cell (2016) 165:867-81. doi: 10.1016/j.cell.2016.04.006

25. Staring J, von Castelmur E, Blomen VA, van den Hengel LG, Brockmann M, Baggen J, et al. PLA2G16 Represents a Switch Between Entry and Clearance of Picornaviridae. Nature (2017) 541:412-6. doi: 10.1038/nature21032

26. Kim N, Kim M-J, Sung PS, Bae YC, Shin E-C, Yoo J-Y. Interferon-Inducible Protein SCOTIN Interferes With HCV Replication Through the Autolysosomal Degradation of NS5A. Nat Commun (2016) 7:10631. doi: $10.1038 /$ ncomms 10631

27. Valera M-S, de Armas-Rillo L, Barroso-González J, Ziglio S, Batisse J, Dubois $\mathrm{N}$, et al. The HDAC6/APOBEC3G Complex Regulates HIV-1 Infectiveness by Inducing Vif Autophagic Degradation. Retrovirology (2015) 12:53. doi: 10.1186/s12977-015-0181-5

28. Ribeiro CMS, Sarrami-Forooshani R, Setiawan LC, Zijlstra-Willems EM, van Hamme JL, Tigchelaar W, et al. Receptor Usage Dictates HIV-1 Restriction by Human TRIM5 $\alpha$ in Dendritic Cell Subsets. Nature (2016) 540:448-52. doi: $10.1038 /$ nature20567

29. Sagnier S, Daussy CF, Borel S, Robert-Hebmann V, Faure M, Blanchet FP, et al. Autophagy Restricts HIV-1 Infection by Selectively Degrading Tat in CD4+ T Lymphocytes. J Virol (2015) 89:615-25. doi: 10.1128/JVI.02174-14

30. Hwang S, Maloney NS, Bruinsma MW, Goel G, Duan E, Zhang L, et al. Nondegradative Role of Atg5-Atg12/Atg16L1 Autophagy Protein Complex in Antiviral Activity of Interferon Gamma. Cell Host Microbe (2012) 11:397409. doi: 10.1016/j.chom.2012.03.002

31. Paludan C, Schmid D, Landthaler M, Vockerodt M, Kube D, Tuschl T, et al. Endogenous MHC Class II Processing of a Viral Nuclear Antigen After Autophagy. Science (2005) 307:593-6. doi: 10.1126/science.1104904

32. Chaumorcel M, Lussignol M, Mouna L, Cavignac Y, Fahie K, Cotte-Laffitte J, et al. The Human Cytomegalovirus Protein TRS1 Inhibits Autophagy via Its Interaction With Beclin 1. J Virol (2012) 86:2571-84. doi: 10.1128/ JVI.05746-11

33. Cuconati A, White E. Viral Homologs of BCL-2: Role of Apoptosis in the Regulation of Virus Infection. Genes Dev (2002) 16:2465-78. doi: 10.1101/ gad.1012702

34. Mouna L, Hernandez E, Bonte D, Brost R, Amazit L, Delgui LR, et al. Analysis of the Role of Autophagy Inhibition by Two Complementary Human Cytomegalovirus BECN1/Beclin 1-Binding Proteins. Autophagy (2016) 12:327-42. doi: 10.1080/15548627.2015.1125071

35. Orvedahl A, Alexander D, Tallóczy Z, Sun Q, Wei Y, Zhang W, et al. HSV-1 ICP34.5 Confers Neurovirulence by Targeting the Beclin 1 Autophagy Protein. Cell Host Microbe (2007) 1:23-35. doi: 10.1016/j.chom. 2006.12.001

36. Bhatt AP, Damania B. Aktivation of PI3K/AKT/Mtor Signaling Pathway by KSHV. Front Immunol (2013) 3:401. doi: 10.3389/fimmu.2012.00401

37. Kanai R, Zaupa C, Sgubin D, Antoszczyk SJ, Martuza RL, Wakimoto H, et al. Effect of $\gamma 34.5$ Deletions on Oncolytic Herpes Simplex Virus Activity in Brain Tumors. J Virol (2012) 86:4420-31. doi: 10.1128/JVI.00017-12

38. Liang Q, Chang B, Brulois KF, Castro K, Min C-K, Rodgers MA, et al. Kaposi's Sarcoma-Associated Herpesvirus K7 Modulates Rubicon-Mediated Inhibition of Autophagosome Maturation. J Virol (2013) 87:12499-503. doi: 10.1128/JVI.01898-13

39. Jackson WT, Giddings THJr, Taylor MP, Mulinyawe S, Rabinovitch M, Kopito RR, et al. Subversion of Cellular Autophagosomal Machinery by RNA Viruses. PloS Biol (2005) 3:e156. doi: 10.1371/journal.pbio.0030156

40. Berryman S, Brooks E, Burman A, Hawes P, Roberts R, Netherton C, et al. Foot-and-Mouth Disease Virus Induces Autophagosomes During Cell Entry via a Class III Phosphatidylinositol 3-Kinase-Independent Pathway. J Virol (2012) 86:12940-53. doi: 10.1128/JVI.00846-12

41. Robinson SM, Tsueng G, Sin J, Mangale V, Rahawi S, McIntyre LL, et al. Coxsackievirus B Exits the Host Cell in Shed Microvesicles Displaying Autophagosomal Markers. PloS Pathog (2014) 10:e1004045. doi: 10.1371/ journal.ppat.1004045

42. Guévin C, Manna D, Bélanger C, Konan KV, Mak P, Labonté P. Autophagy Protein ATG5 Interacts Transiently With the Hepatitis C Virus RNA
Polymerase (NS5B) Early During Infection. Virology (2010) 405:1-7. doi: 10.1016/j.virol.2010.05.032

43. Wang L, Tian Y, Ou JJ. HCV Induces the Expression of Rubicon and UVRAG to Temporally Regulate the Maturation of Autophagosomes and Viral Replication. PloS Pathog (2015) 11:e1004764. doi: 10.1371/ journal.ppat.1004764

44. Ding B, Zhang G, Yang X, Zhang S, Chen L, Yan Q, et al. Phosphoprotein of Human Parainfluenza Virus Type 3 Blocks Autophagosome-Lysosome Fusion to Increase Virus Production. Cell Host Microbe (2014) 15:564-77. doi: 10.1016/j.chom.2014.04.004

45. Zhou Z, Jiang X, Liu D, Fan Z, Hu X, Yan J, et al. Autophagy Is Involved in Influenza a Virus Replication. Autophagy (2009) 5:321-8. doi: 10.4161/ auto.5.3.7406

46. Plummer M, de Martel C, Vignat J, Ferlay J, Bray F, Franceschi S. Globa Burden of Cancers Attributable to Infections in 2012: A Synthetic Analysis. Lancet Glob Health (2016) 4:e609-16. doi: 10.1016/S2214-109X(16)30143-7

47. Mesri EA, Feitelson MA, Munger K. Human Viral Oncogenesis: A Cancer Hallmarks Analysis. Cell Host Microbe (2014) 15:266-82. doi: 10.1016/ j.chom.2014.02.011

48. Matsuda Y, Ichida T. Impact of Hepatitis B Virus X Protein on the DNA Damage Response During Hepatocarcinogenesis. Med Mol Morphol (2009) 42:138-42. doi: 10.1007/s00795-009-0457-8

49. Moody CA, Laimins LA. Human Papillomavirus Oncoproteins: Pathways to Transformation. Nat Rev Cancer (2010) 10:550-60. doi: 10.1038/nrc2886

50. Zane L, Yasunaga J, Mitagami Y, Yedavalli V, Tang S-W, Chen C-Y, et al. Wipl and P53 Contribute to HTLV-1 Tax-Induced Tumorigenesis. Retrovirology (2012) 9:114. doi: 10.1186/1742-4690-9-114

51. Radkov SA, Kellam P, Boshoff C. The Latent Nuclear Antigen of Kaposi Sarcoma-Associated Herpesvirus Targets the Retinoblastoma-E2F Pathway and With the Oncogene Hras Transforms Primary Rat Cells. Nat Med (2000) 6:1121-7. doi: 10.1038/80459

52. Friborg J, Kong W, Hottiger MO, Nabel GJ. P53 Inhibition by the LANA Protein of KSHV Protects Against Cell Death. Nature (1999) 402:889-94. doi: $10.1038 / 47266$

53. Borchert S, Czech-Sioli M, Neumann F, Schmidt C, Wimmer P, Dobner T, et al. High-Affinity Rb Binding, P53 Inhibition, Subcellular Localization, and Transformation by Wild-Type or Tumor-Derived Shortened Merkel Cell Polyomavirus Large T Antigens. J Virol (2014) 88:3144-60. doi: 10.1128/ JVI.02916-13

54. Choi BH, Choi M, Jeon HY, Rho HM. Hepatitis B Viral X Protein Overcomes Inhibition of E2F1 Activity by Prb on the Human Rb Gene Promoter. DNA Cell Biol (2001) 20:75-80. doi: 10.1089/104454901750070274

55. Hesbacher S, Pfitzer L, Wiedorfer K, Angermeyer S, Borst A, Haferkamp S et al. RB1 Is the Crucial Target of the Merkel Cell Polyomavirus Large T Antigen in Merkel Cell Carcinoma Cells. Oncotarget (2016) 7:32956-68. doi: 10.18632/oncotarget.8793

56. Husaini R, Ahmad M, Soo-Beng Khoo A. Epstein-Barr Virus Latent Membrane Protein LMP1 Reduces P53 Protein Levels Independent of the PI3K-Akt Pathway. BMC Res Notes (2011) 4:551. doi: 10.1186/1756-0500-4-551

57. Bernard X, Robinson P, Nominé Y, Masson M, Charbonnier S, RamirezRamos JR, et al. Proteasomal Degradation of P53 by Human Papillomavirus E6 Oncoprotein Relies on the Structural Integrity of P53 Core Domain. PloS One (2011) 6:e25981. doi: 10.1371/journal.pone.0025981

58. Parroche P, Touka M, Mansour M, Bouvard V, Thépot A, Accardi R, et al. Human Papillomavirus Type 16 E6 Inhibits P21waf1 Transcription Independently of P53 by Inactivating p150Sal2. Virology (2011) 417:443-8. doi: 10.1016/j.virol.2011.05.016

59. Shin M-K, Balsitis S, Brake T, Lambert PF. Human Papillomavirus E7 Oncoprotein Overrides the Tumor Suppressor Activity of p21Cip1 in Cervical Carcinogenesis. Cancer Res (2009) 69:5656-63. doi: 10.1158/ 0008-5472.CAN-08-3711

60. Yan X, Shah W, Jing L, Chen H, Wang Y. High-Risk Human Papillomavirus Type 18 E7 Caused P27 Elevation and Cytoplasmic Localization. Cancer Biol Ther (2010) 9:728-35. doi: 10.4161/cbt.9.9.11442

61. Hu Z, Zhu D, Wang W, Li W, Jia W, Zeng X, et al. Genome-Wide Profiling of HPV Integration in Cervical Cancer Identifies Clustered Genomic Hot Spots and a Potential Microhomology-Mediated Integration Mechanism. Nat Genet (2015) 47:158-63. doi: 10.1038/ng.3178 
62. Mutz P, Metz P, Lempp FA, Bender S, Qu B, Schöneweis K, et al. HBV Bypasses the Innate Immune Response and Does Not Protect HCV From Antiviral Activity of Interferon. Gastroenterology (2018) 154:1791-1804.e22. doi: 10.1053/j.gastro.2018.01.044

63. Garaigorta U, Chisari FV. Hepatitis C Virus Blocks Interferon Effector Function by Inducing Protein Kinase R Phosphorylation. Cell Host Microbe (2009) 6:513-22. doi: 10.1016/j.chom.2009.11.004

64. Kang W, Sung PS, Park S-H, Yoon S, Chang D-Y, Kim S, et al. Hepatitis C Virus Attenuates Interferon-Induced Major Histocompatibility Complex Class I Expression and Decreases CD8+ T Cell Effector Functions. Gastroenterology (2014) 146:1351-60. doi: 10.1053/j.gastro.2014.01.054

65. Chen Y, Cheng M, Tian Z. Hepatitis B Virus Down-Regulates Expressions of MHC Class I Molecules on Hepatoplastoma Cell Line. Cell Mol Immunol (2006) 3:373-8.

66. Park JS, Kim EJ, Kwon HJ, Hwang ES, Namkoong SE, Um SJ. Inactivation of Interferon Regulatory Factor-1 Tumor Suppressor Protein by HPV E7 Oncoprotein. Implication for the E7-Mediated Immune Evasion Mechanism in Cervical Carcinogenesis. J Biol Chem (2000) 275:6764-9. doi: 10.1074/jbc.275.10.6764

67. Ashrafi GH, Haghshenas MR, Marchetti B, O’Brien PM, Campo MS. E5 Protein of Human Papillomavirus Type 16 Selectively Downregulates Surface HLA Class I. Int J Cancer (2005) 113:276-83. doi: 10.1002/ijc.20558

68. Paulson KG, Tegeder A, Willmes C, Iyer JG, Afanasiev OK, Schrama D, et al. Downregulation of MHC-I Expression Is Prevalent But Reversible in Merkel Cell Carcinoma. Cancer Immunol Res (2014) 2:1071-9. doi: 10.1158/23266066.CIR-14-0005

69. Griffiths DA, Abdul-Sada H, Knight LM, Jackson BR, Richards K, Prescott EL, et al. Merkel Cell Polyomavirus Small T Antigen Targets the NEMO Adaptor Protein to Disrupt Inflammatory Signaling. J Virol (2013) 87:13853-67. doi: 10.1128/JVI.02159-13

70. Zhang T, Lin R-T, Li Y, Douglas SD, Maxcey C, Ho C, et al. Hepatitis C Virus Inhibits Intracellular Interferon Alpha Expression in Human Hepatic Cell Lines. Hepatol Baltim Md (2005) 42:819-27. doi: 10.1002/hep.20854

71. Sathish N, Yuan Y. Evasion and Subversion of Interferon-Mediated Antiviral Immunity by Kaposi's Sarcoma-Associated Herpesvirus: An Overview. J Virol (2011) 85:10934-44. doi: 10.1128/JVI.00687-11

72. Tomescu C, Law WK, Kedes DH. Surface Downregulation of Major Histocompatibility Complex Class I, PE-CAM, and ICAM-1 Following De Novo Infection of Endothelial Cells With Kaposi's Sarcoma-Associated Herpesvirus. J Virol (2003) 77:9669-84. doi: 10.1128/jvi.77.17.9669-9684.2003

73. Geiger TR, Martin JM. The Epstein-Barr Virus-Encoded LMP-1 Oncoprotein Negatively Affects Tyk2 Phosphorylation and Interferon Signaling in Human B Cells. J Virol (2006) 80:11638-50. doi: 10.1128/ JVI.01570-06

74. Ressing ME, Horst D, Griffin BD, Tellam J, Zuo J, Khanna R, et al. EpsteinBarr Virus Evasion of CD8(+) and CD4(+) T Cell Immunity via Concerted Actions of Multiple Gene Products. Semin Cancer Biol (2008) 18:397-408. doi: 10.1016/j.semcancer.2008.10.008

75. Chretien A-S, Le Roy A, Vey N, Prebet T, Blaise D, Fauriat C, et al. CancerInduced Alterations of NK-Mediated Target Recognition: Current and Investigational Pharmacological Strategies Aiming at Restoring NKMediated Anti-Tumor Activity. Front Immunol (2014) 5:122. doi: 10.3389/ fimmu.2014.00122

76. Kim MS, Jeong EG, Ahn CH, Kim SS, Lee SH, Yoo NJ. Frameshift Mutation of UVRAG, an Autophagy-Related Gene, in Gastric Carcinomas With Microsatellite Instability. Hum Pathol (2008) 39:1059-63. doi: 10.1016/ j.humpath.2007.11.013

77. He S, Zhao Z, Yang Y, O'Connell D, Zhang X, Oh S, et al. Truncating Mutation in the Autophagy Gene UVRAG Confers Oncogenic Properties and Chemosensitivity in Colorectal Cancers. Nat Commun (2015) 6:7839. doi: $10.1038 /$ ncomms 8839

78. Knævelsrud H, Ahlquist T, Merok MA, Nesbakken A, Stenmark H, Lothe RA, et al. UVRAG Mutations Associated With Microsatellite Unstable Colon Cancer do Not Affect Autophagy. Autophagy (2010) 6:863-70. doi: 10.4161/auto.6.7.13033

79. Liang C, Feng P, Ku B, Oh B-H, Jung JU. UVRAG: A New Player in Autophagy and Tumor Cell Growth. Autophagy (2007) 3:69-71. doi: $10.4161 /$ auto. 3437
80. Takamura A, Komatsu M, Hara T, Sakamoto A, Kishi C, Waguri S, et al. Autophagy-Deficient Mice Develop Multiple Liver Tumors. Genes Dev (2011) 25:795-800. doi: 10.1101/gad.2016211

81. Galluzzi L, Pietrocola F, Bravo-San Pedro JM, Amaravadi RK, Baehrecke $\mathrm{EH}$, Cecconi F, et al. Autophagy in Malignant Transformation and Cancer Progression. EMBO J (2015) 34:856-80. doi: 10.15252/embj.201490784

82. Suares A, Medina MV, Coso O. Autophagy in Viral Development and Progression of Cancer. Front Oncol (2021) 11:603224. doi: 10.3389/ fonc.2021.603224

83. Vescovo T, Pagni B, Piacentini M, Fimia GM, Antonioli M. Regulation of Autophagy in Cells Infected With Oncogenic Human Viruses and its Impact on Cancer Development. Front Cell Dev Biol (2020) 8:47. doi: 10.3389/ fcell.2020.00047

84. Surviladze Z, Sterk RT, DeHaro SA, Ozbun MA. Cellular Entry of Human Papillomavirus Type 16 Involves Activation of the Phosphatidylinositol 3Kinase/Akt/Mtor Pathway and Inhibition of Autophagy. J Virol (2013) 87:2508-17. doi: 10.1128/JVI.02319-12

85. Belleudi F, Nanni M, Raffa S, Torrisi MR. HPV16 E5 Deregulates the Autophagic Process in Human Keratinocytes. Oncotarget (2015) 6:937086. doi: 10.18632/oncotarget.3326

86. Mattoscio D, Casadio C, Miccolo C, Maffini F, Raimondi A, Tacchetti C, et al. Autophagy Regulates UBC9 Levels During Viral-Mediated Tumorigenesis. PloS Pathog (2017) 13:e1006262. doi: 10.1371/journal.ppat.1006262

87. Lai K, Matthews S, Wilmott JS, Killingsworth MC, Yong JL, Caixeiro NJ, et al. Differences in LC3B Expression and Prognostic Implications in Oropharyngeal and Oral Cavity Squamous Cell Carcinoma Patients. BMC Cancer (2018) 18:624. doi: 10.1186/s12885-018-4536-x

88. Carchman EH, Matkowskyj KA, Meske L, Lambert PF. Dysregulation of Autophagy Contributes to Anal Carcinogenesis. PloS One (2016) 11: e0164273. doi: 10.1371/journal.pone.0164273

89. Khan M, Imam H, Siddiqui A. Subversion of Cellular Autophagy During Virus Infection: Insights From Hepatitis B and Hepatitis C Viruses. Liver Res (2018) 2:146-56. doi: 10.1016/j.livres.2018.09.002

90. Mizui T, Yamashina S, Tanida I, Takei Y, Ueno T, Sakamoto N, et al. Inhibition of Hepatitis C Virus Replication by Chloroquine Targeting VirusAssociated Autophagy. J Gastroenterol (2010) 45:195-203. doi: 10.1007/ s00535-009-0132-9

91. Tian Y, Sir D, Kuo C-F, Ann DK, Ou J-HJ. Autophagy Required for Hepatitis B Virus Replication in Transgenic Mice. J Virol (2011) 85:13453-6. doi: 10.1128/JVI.06064-11

92. Liu B, Fang M, Hu Y, Huang B, Li N, Chang C, et al. Hepatitis B Virus X Protein Inhibits Autophagic Degradation by Impairing Lysosomal Maturation. Autophagy (2014) 10:416-30. doi: 10.4161/auto.27286

93. Lan S-H, Wu S-Y, Zuchini R, Lin X-Z, Su I-J, Tsai T-F, et al. Autophagy Suppresses Tumorigenesis of Hepatitis B Virus-Associated Hepatocellular Carcinoma Through Degradation of Microrna-224. Hepatol Baltim Md (2014) 59:505-17. doi: 10.1002/hep.26659

94. Shin G-C, Kang HS, Lee AR, Kim K-H. Hepatitis B Virus-Triggered Autophagy Targets TNFRSF10B/Death Receptor 5 for Degradation to Limit TNFSF10/TRAIL Response. Autophagy (2016) 12:2451-66. doi: 10.1080/15548627.2016.1239002

95. Luo MXM, Wong SH, Chan MTV, Yu L, Yu SSB, Wu F, et al. Autophagy Mediates Hbx-Induced Nuclear Factor- $\kappa b$ Activation and Release of IL-6, IL-8, and CXCL2 in Hepatocytes. J Cell Physiol (2015) 230:2382-9. doi: $10.1002 /$ jcp. 24967

96. Wong VW-S, Yu J, Cheng AS-L, Wong GL-H, Chan H-Y, Chu ES-H, et al. High Serum Interleukin-6 Level Predicts Future Hepatocellular Carcinoma Development in Patients With Chronic Hepatitis B. Int J Cancer (2009) 124:2766-70. doi: 10.1002/ijc.24281

97. Wang L, Tian Y, Ou JJ. HCV Induces the Expression of Rubicon and UVRAG to Temporally Regulate the Maturation of Autophagosomes and Viral Replication. PloS Pathog (2015) 11:e1004764. doi: 10.1371/ journal.ppat.1004764

98. Chu JYK, Ou J-HJ. Autophagy in HCV Replication and Protein Trafficking. Int J Mol Sci (2021) 22:1089. doi: 10.3390/ijms22031089

99. Fu N, Du H, Li D, Lu Y, Li W, Wang Y, et al. Clusterin Contributes to Hepatitis C Virus-Related Hepatocellular Carcinoma by Regulating Autophagy. Life Sci (2020) 256:117911. doi: 10.1016/j.lfs.2020.117911 
100. Saito T, Ichimura Y, Taguchi K, Suzuki T, Mizushima T, Takagi K, et al. P62/ Sqstm1 Promotes Malignancy of HCV-Positive Hepatocellular Carcinoma Through Nrf2-Dependent Metabolic Reprogramming. Nat Commun (2016) 7:12030. doi: 10.1038/ncomms12030

101. Yan L, Majerciak V, Zheng Z-M, Lan K. Towards Better Understanding of KSHV Life Cycle: From Transcription and Posttranscriptional Regulations to Pathogenesis. Virol Sin (2019) 34:135-61. doi: 10.1007/s12250-019-00114-3

102. Yin H, Qu J, Peng Q, Gan R. Molecular Mechanisms of EBV-Driven Cell Cycle Progression and Oncogenesis. Med Microbiol Immunol (Berl) (2019) 208:573-83. doi: 10.1007/s00430-018-0570-1

103. Lee J-S, Li Q, Lee J-Y, Lee S-H, Jeong JH, Lee H-R, et al. FLIP-Mediated Autophagy Regulation in Cell Death Control. Nat Cell Biol (2009) 11:1355. doi: $10.1038 /$ ncb1980

104. White E. Autophagy and P53. Cold Spring Harb Perspect Med (2016) 6: a026120. doi: 10.1101/cshperspect.a026120

105. Bhatt AP, Damania B. Aktivation of PI3K/AKT/Mtor Signaling Pathway by KSHV. Front Immunol (2012) 3:401. doi: 10.3389/fimmu.2012.00401

106. Pattingre S, Tassa A, Qu X, Garuti R, Liang XH, Mizushima N, et al. Bcl-2 Antiapoptotic Proteins Inhibit Beclin 1-Dependent Autophagy. Cell (2005) 122:927-39. doi: 10.1016/j.cell.2005.07.002

107. Zhang T, Dong K, Liang W, Xu D, Xia H, Geng J, et al. G-Protein-Coupled Receptors Regulate Autophagy by ZBTB16-Mediated Ubiquitination and Proteasomal Degradation of Atg14L. eLife (2015) 4:e06734. doi: 10.7554/ eLife.06734

108. Liang Q, Chang B, Brulois KF, Castro K, Min C-K, Rodgers MA, et al. Kaposi's Sarcoma-Associated Herpesvirus K7 Modulates Rubicon-Mediated Inhibition of Autophagosome Maturation. J Virol (2013) 87:12499-503. doi: 10.1128/JVI.01898-13

109. Meng W, Gao S-J. Targeting XPO1 Enhances Innate Immune Response and Inhibits KSHV Lytic Replication During Primary Infection by Nuclear Stabilization of the P62 Autophagy Adaptor Protein. Cell Death Dis (2021) 12:29. doi: 10.1038/s41419-020-03303-1

110. Leidal AM, Cyr DP, Hill RJ, Lee PWK, McCormick C. Subversion of Autophagy by Kaposi's Sarcoma-Associated Herpesvirus Impairs Oncogene-Induced Senescence. Cell Host Microbe (2012) 11:167-80. doi: 10.1016/j.chom.2012.01.005

111. Moody CA, Scott RS, Amirghahari N, Nathan C-A, Young LS, Dawson CW, et al. Modulation of the Cell Growth Regulator Mtor by Epstein-Barr VirusEncoded LMP2A. J Virol (2005) 79:5499. doi: 10.1128/JVI.79.9.54995506.2005

112. Shao Z, Borde C, Quignon F, Escargueil A, Maréchal V. Epstein-Barr Virus BALF0 and BALF1 Modulate Autophagy. Viruses (2019) 11(12):1099. doi: $10.3390 / \mathrm{v} 11121099$

113. Granato M, Santarelli R, Farina A, Gonnella R, Lotti LV, Faggioni A, et al. Epstein-Barr Virus Blocks the Autophagic Flux and Appropriates the Autophagic Machinery to Enhance Viral Replication. J Virol (2014) 88:12715. doi: 10.1128/JVI.02199-14

114. Wang L, Howell MEA, Sparks-Wallace A, Hawkins C, Nicksic CA, Kohne C, et al. P62-Mediated Selective Autophagy Endows Virus-Transformed Cells With Insusceptibility to DNA Damage Under Oxidative Stress. PloS Pathog (2019) 15(4):e1007541. doi: 10.1371/journal.ppat.1007541

115. Wang W, Zhang Y, Liu W, Zhang X, Xiao H, Zhao M, et al. CXCR4 Induces Cell Autophagy and Maintains EBV Latent Infection in Ebvagc. Theranostics (2020) 10:11549-61. doi: 10.7150/thno.44251

116. Ducasa N, Grasso D, Benencio P, Papademetrio DL, Biglione M, Kashanchi F, et al. Autophagy in Human T-Cell Leukemia Virus Type 1 (HTLV-1) Induced Leukemia. Front Oncol (2021) 11:641269. doi: 10.3389/ fonc.2021.641269

117. Ren T, Takahashi Y, Liu X, Loughran TP, Sun S-C, Wang H-G, et al. HTLV1 Tax Deregulates Autophagy by Recruiting Autophagic Molecules Into Lipid Raft Microdomains. Oncogene (2015) 34:334-45. doi: 10.1038/ onc. 2013.552

118. Tang S-W, Chen C-Y, Klase Z, Zane L, Jeang K-T. The Cellular Autophagy Pathway Modulates Human T-Cell Leukemia Virus Type 1 Replication. J Virol (2013) 87:1699-707. doi: 10.1128/JVI.02147-12

119. Mukai R, Ohshima T. HTLV-1 HBZ Positively Regulates the Mtor Signaling Pathway via Inhibition of GADD34 Activity in the Cytoplasm. Oncogene (2014) 33:2317-28. doi: 10.1038/onc.2013.181
120. Kumar S, Xie H, Shi H, Gao J, Juhlin CC, Björnhagen V, et al. Merkel Cell Polyomavirus Oncoproteins Induce Micrornas That Suppress Multiple Autophagy Genes. Int J Cancer (2020) 146:1652-66. doi: 10.1002/ijc.32503

121. Martin NT, Bell JC. Oncolytic Virus Combination Therapy: Killing One Bird With Two Stones. Mol Ther (2018) 26:1414-22. doi: 10.1016/j.ymthe. 2018.04.001

122. Russell SJ, Peng K-W. Oncolytic Virotherapy: A Contest Between Apples and Oranges. Mol Ther (2017) 25:1107-16. doi: 10.1016/j.ymthe.2017.03.026

123. Bai Y, Hui P, Du X, Su X. Updates to the Antitumor Mechanism of Oncolytic Virus. Thorac Cancer (2019) 10:1031-5. doi: 10.1111/1759-7714.13043

124. Lin L, Baehrecke EH. Autophagy, Cell Death, and Cancer. Mol Cell Oncol (2015) 2:e985913. doi: 10.4161/23723556.2014.985913

125. Galluzzi L, Vitale I, Abrams JM, Alnemri ES, Baehrecke EH, Blagosklonny MV, et al. Molecular Definitions of Cell Death Subroutines: Recommendations of the Nomenclature Committee on Cell Death 2012. Cell Death Differ (2012) 19:107-20. doi: 10.1038/cdd.2011.96

126. Berry DL, Baehrecke EH. Growth Arrest and Autophagy Are Required for Salivary Gland Cell Degradation in Drosophila. Cell (2007) 131:1137-48. doi: 10.1016/j.cell.2007.10.048

127. Linder B, Kögel D. Autophagy in Cancer Cell Death. Biology (2019) 8(4):82. doi: 10.3390/biology8040082

128. Grekova SP, Raykov Z, Zawatzky R, Rommelaere J, Koch U. Activation of a Glioma-Specific Immune Response by Oncolytic Parvovirus Minute Virus of Mice Infection. Cancer Gene Ther (2012) 19:468-75. doi: 10.1038/ cgt.2012.20

129. Moehler M, Zeidler M, Schede J, Rommelaere J, Galle PR, Cornelis JJ, et al. Oncolytic Parvovirus H1 Induces Release of Heat-Shock Protein HSP72 in Susceptible Human Tumor Cells But may Not Affect Primary Immune Cells. Cancer Gene Ther (2003) 10:477-80. doi: 10.1038/sj.cgt.7700591

130. Elankumaran S, Rockemann D, Samal SK. Newcastle Disease Virus Exerts Oncolysis by Both Intrinsic and Extrinsic Caspase-Dependent Pathways of Cell Death. J Virol (2006) 80:7522-34. doi: 10.1128/JVI.00241-06

131. Whilding LM, Archibald KM, Kulbe H, Balkwill FR, Öberg D, McNeish IA. Vaccinia Virus Induces Programmed Necrosis in Ovarian Cancer Cells. Mol Ther (2013) 21:2074-86. doi: 10.1038/mt.2013.195

132. Jin K-T, Tao X-H, Fan Y-B, Wang S-B. Crosstalk Between Oncolytic Viruses and Autophagy in Cancer Therapy. BioMed Pharmacother Biomed Pharmacother (2021) 134:110932. doi: 10.1016/j.biopha.2020.110932

133. Tazawa H, Kagawa S, Fujiwara T. Oncolytic Adenovirus-Induced Autophagy: Tumor-Suppressive Effect and Molecular Basis. Acta Med Okayama (2013) 67:333-42. doi: 10.18926/AMO/52006

134. Ito H, Aoki H, Kühnel F, Kondo Y, Kubicka S, Wirth T, et al. Autophagic Cell Death of Malignant Glioma Cells Induced by a Conditionally Replicating Adenovirus. JNCI J Natl Cancer Inst (2006) 98:625-36. doi: 10.1093/jnci/djj161

135. Tazawa H, Yano S, Yoshida R, Yamasaki Y, Sasaki T, Hashimoto Y, et al. Genetically Engineered Oncolytic Adenovirus Induces Autophagic Cell Death Through an E2F1-Microrna-7-Epidermal Growth Factor Receptor Axis. Int J Cancer (2012) 131:2939-50. doi: 10.1002/ijc.27589

136. Ulasov IV, Tyler MA, Zhu ZB, Han Y, He T-C, Lesniak MS. Oncolytic Adenoviral Vectors Which Employ the Survivin Promoter Induce Glioma Oncolysis via a Process of Beclin-Dependent Autophagy. Int J Oncol (2009) 34:729-42. doi: 10.3892/ijo_00000199

137. Tazawa H, Kuroda S, Hasei J, Kagawa S, Fujiwara T. Impact of Autophagy in Oncolytic Adenoviral Therapy for Cancer. Int J Mol Sci (2017) 18(7):1479. doi: 10.3390/ijms18071479

138. Rodriguez-Rocha H, Gomez-Gutierrez JG, Garcia-Garcia A, Rao X-M, Chen L, McMasters KM, et al. Adenoviruses Induce Autophagy to Promote Virus Replication and Oncolysis. Virology (2011) 416:9-15. doi: 10.1016/ j.virol.2011.04.017

139. Furukawa Y, Takasu A, Yura Y. Role of Autophagy in Oncolytic Herpes Simplex Virus Type 1-Induced Cell Death in Squamous Cell Carcinoma Cells. Cancer Gene Ther (2017) 24:393-400. doi: 10.1038/cgt.2017.33

140. Bu X, Zhao Y, Zhang Z, Wang M, Li M, Yan Y. Recombinant Newcastle Disease Virus (Rl-RVG) Triggers Autophagy and Apoptosis in Gastric Carcinoma Cells by Inducing ER Stress. Am J Cancer Res (2016) 6:924-36.

141. Meng C, Zhou Z, Jiang K, Yu S, Jia L, Wu Y, et al. Newcastle Disease Virus Triggers Autophagy in U251 Glioma Cells to Enhance Virus Replication. Arch Virol (2012) 157:1011-8. doi: 10.1007/s00705-012-1270-6 
142. Jiang K, Li Y, Zhu Q, Xu J, Wang Y, Deng W, et al. Pharmacological Modulation of Autophagy Enhances Newcastle Disease Virus-Mediated Oncolysis in Drug-Resistant Lung Cancer Cells. BMC Cancer (2014) 14:551. doi: 10.1186/1471-2407-14-551

143. Xia M, Gonzalez P, Li C, Meng G, Jiang A, Wang H, et al. Mitophagy Enhances Oncolytic Measles Virus Replication by Mitigating DDX58/RIG-I-Like Receptor Signaling. J Virol (2014) 88:5152-64. doi: 10.1128/JVI.03851-13

144. Xia M, Meng G, Jiang A, Chen A, Dahlhaus M, Gonzalez P, et al. Mitophagy Switches Cell Death From Apoptosis to Necrosis in NSCLC Cells Treated With Oncolytic Measles Virus. Oncotarget (2014) 5:3907-18. doi: 10.18632/ oncotarget.2028

145. Tong Y, You L, Liu H, Li L, Meng H, Qian Q, et al. Potent Antitumor Activity of Oncolytic Adenovirus Expressing Beclin-1 via Induction of Autophagic Cell Death in Leukemia. Oncotarget (2013) 4:860-74. doi: 10.18632/ oncotarget.1018

146. Lei W, Wang S, Xu N, Chen Y, Wu G, Zhang A, et al. Enhancing Therapeutic Efficacy of Oncolytic Vaccinia Virus Armed With Beclin-1, an Autophagic Gene in Leukemia and Myeloma. BioMed Pharmacother (2020) 125:110030. doi: 10.1016/j.biopha.2020.110030

147. de Matos AL, Franco LS, McFadden G. Oncolytic Viruses and the Immune System: The Dynamic Duo. Mol Ther - Methods Clin Dev (2020) 17:349-58. doi: 10.1016/j.omtm.2020.01.001

148. Kepp O, Senovilla L, Vitale I, Vacchelli E, Adjemian S, Agostinis P, et al. Consensus Guidelines for the Detection of Immunogenic Cell Death. OncoImmunology (2014) 3:e955691. doi: 10.4161/21624011.2014.955691

149. Donnelly OG, Errington-Mais F, Steele L, Hadac E, Jennings V, Scott K, et al. Measles Virus Causes Immunogenic Cell Death in Human Melanoma. Gene Ther (2013) 20:7-15. doi: 10.1038/gt.2011.205

150. Endo Y, Sakai R, Ouchi M, Onimatsu H, Hioki M, Kagawa S, et al. VirusMediated Oncolysis Induces Danger Signal and Stimulates Cytotoxic TLymphocyte Activity via Proteasome Activator Upregulation. Oncogene (2008) 27:2375-81. doi: 10.1038/sj.onc.1210884

151. Grekova SP, Raykov Z, Zawatzky R, Rommelaere J, Koch U. Activation of a Glioma-Specific Immune Response by Oncolytic Parvovirus Minute Virus of Mice Infection. Cancer Gene Ther (2012) 19:468-75. doi: 10.1038/ cgt. 2012.20

152. Miyamoto S, Inoue H, Nakamura T, Yamada M, Sakamoto C, Urata Y, et al. Coxsackievirus B3 Is an Oncolytic Virus With Immunostimulatory Properties That Is Active Against Lung Adenocarcinoma. Cancer Res (2012) 72:2609-21. doi: 10.1158/0008-5472.CAN-11-3185

153. Zhang Y, Chirmule N, Gao G, Qian R, Croyle M, Joshi B, et al. Acute Cytokine Response to Systemic Adenoviral Vectors in Mice Is Mediated by Dendritic Cells and Macrophages. Mol Ther (2001) 3:697-707. doi: 10.1006/ mthe.2001.0329

154. Qu X, Zou Z, Sun Q, Luby-Phelps K, Cheng P, Hogan RN, et al. Autophagy Gene-Dependent Clearance of Apoptotic Cells During Embryonic Development. Cell (2007) 128:931-46. doi: 10.1016/j.cell.2006.12.044

155. Michaud M, Martins I, Sukkurwala AQ, Adjemian S, Ma Y, Pellegatti P, et al. Autophagy-Dependent Anticancer Immune Responses Induced by Chemotherapeutic Agents in Mice. Science (2011) 334:1573-7. doi: $10.1126 /$ science. 1208347

156. Ko A, Kanehisa A, Martins I, Senovilla L, Chargari C, Dugue D, et al. Autophagy Inhibition Radiosensitizes In Vitro, Yet Reduces Radioresponses In Vivo Due to Deficient Immunogenic Signalling. Cell Death Differ (2014) 21:92-9. doi: 10.1038/cdd.2013.124

157. Thorburn J, Horita H, Redzic J, Hansen K, Frankel AE, Thorburn A. Autophagy Regulates Selective HMGB1 Release in Tumor Cells That Are Destined to Die. Cell Death Differ (2009) 16:175-83. doi: 10.1038/ cdd.2008.143

158. You L, Jin S, Zhu L, Qian W. Autophagy, Autophagy-Associated Adaptive Immune Responses and its Role in Hematologic Malignancies. Oncotarget (2016) 8:12374-88. doi: 10.18632/oncotarget.13583

159. Crotzer VL, Blum JS. Autophagy and its Role in MHC-Mediated Antigen Presentation. J Immunol Baltim Md 1950 (2009) 182:3335-41. doi: 10.4049/ jimmunol.0803458

160. Li Y, Wang L-X, Yang G, Hao F, Urba WJ, Hu H-M. Efficient CrossPresentation Depends on Autophagy in Tumor Cells. Cancer Res (2008) 68:6889-95. doi: 10.1158/0008-5472.CAN-08-0161
161. Liikanen I, Ahtiainen L, Hirvinen ML, Bramante S, Cerullo V, Nokisalmi P, et al. Oncolytic Adenovirus With Temozolomide Induces Autophagy and Antitumor Immune Responses in Cancer Patients. Mol Ther (2013) 21:121223. doi: $10.1038 / \mathrm{mt} .2013 .51$

162. Klein SR, Jiang H, Hossain MB, Fan X, Gumin J, Dong A, et al. Critical Role of Autophagy in the Processing of Adenovirus Capsid-Incorporated CancerSpecific Antigens. PloS One (2016) 11:e0153814. doi: 10.1371/ journal.pone.0153814

163. Keshavarz M, Solaymani-Mohammadi F, Miri SM, Ghaemi A. Oncolytic Paramyxoviruses-Induced Autophagy; A Prudent Weapon for Cancer Therapy. J BioMed Sci (2019) 26:48. doi: 10.1186/s12929-019-0542-9

164. Koks CA, Garg AD, Ehrhardt M, Riva M, Vandenberk L, Boon L, et al. Newcastle Disease Virotherapy Induces Long-Term Survival and TumorSpecific Immune Memory in Orthotopic Glioma Through the Induction of Immunogenic Cell Death. Int J Cancer (2015) 136:E313-325. doi: 10.1002/ ijc. 29202

165. Ye T, Jiang K, Wei L, Barr MP, Xu Q, Zhang G, et al. Oncolytic Newcastle Disease Virus Induces Autophagy-Dependent Immunogenic Cell Death in Lung Cancer Cells. Am J Cancer Res (2018) 8:1514-27.

166. Bollino D, Colunga A, Li B, Aurelian L. $\triangle \mathrm{PK}$ Oncolytic Activity Includes Modulation of the Tumour Cell Milieu. J Gen Virol (2016) 97:496-508. doi: 10.1099/jgv.0.000353

167. White E, Mehnert JM, Chan CS. Autophagy, Metabolism, and Cancer. Clin Cancer Res Off J Am Assoc Cancer Res (2015) 21:5037-46. doi: 10.1158/10780432.CCR-15-0490

168. Daskalaki I, Gkikas I, Tavernarakis N. Hypoxia and Selective Autophagy in Cancer Development and Therapy. Front Cell Dev Biol (2018) 6:104. doi: 10.3389/fcell.2018.00104

169. Masoud GN, Li W. Hif-1 $\alpha$ Pathway: Role, Regulation and Intervention for Cancer Therapy. Acta Pharm Sin B (2015) 5:378-89. doi: 10.1016/ j.apsb.2015.05.007

170. Schmukler E, Kloog Y, Pinkas-Kramarski R. Ras and Autophagy in Cancer Development and Therapy. Oncotarget (2014) 5:577-86. doi: 10.18632/ oncotarget.1775

171. Mariño G, Niso-Santano M, Baehrecke EH, Kroemer G. Self-Consumption: The Interplay of Autophagy and Apoptosis. Nat Rev Mol Cell Biol (2014) 15:81-94. doi: 10.1038/nrm3735

172. Datan E, Roy SG, Germain G, Zali N, McLean JE, Golshan G, et al. DengueInduced Autophagy, Virus Replication and Protection From Cell Death Require ER Stress (PERK) Pathway Activation. Cell Death Dis (2016) 7: e2127-7. doi: 10.1038/cddis.2015.409

173. McLean JE, Wudzinska A, Datan E, Quaglino D, Zakeri Z. Flavivirus NS4AInduced Autophagy Protects Cells Against Death and Enhances Virus Replication *. J Biol Chem (2011) 286:22147-59. doi: 10.1074/ jbc.M110.192500

174. Mao Y, Da L, Tang H, Yang J, Lei Y, Tiollais P, et al. Hepatitis B Virus X Protein Reduces Starvation-Induced Cell Death Through Activation of Autophagy and Inhibition of Mitochondrial Apoptotic Pathway. Biochem Biophys Res Commun (2011) 415:68-74. doi: 10.1016/j.bbrc.2011.10.013

175. Quan M, Liu S, Zhou L, Feng S, Zhang Y, Cheng J. Hepatitis C Virus Nonstructural 5A Protein Inhibits the Starvation-Induced Apoptosis of Hepatoblastoma Cells by Increasing Beclin 1 Expression. Oncol Rep (2019) 41:3051-9. doi: 10.3892/or.2019.7060

176. Wang W, Zhou J, Shi J, Zhang Y, Liu S, Liu Y, et al. Human T-Cell Leukemia Virus Type 1 Tax-Deregulated Autophagy Pathway and C-FLIP Expression Contribute to Resistance Against Death Receptor-Mediated Apoptosis. J Virol (2014) 88:2786-98. doi: 10.1128/JVI.03025-13

177. Li M, Li J, Zeng R, Yang J, Liu J, Zhang Z, et al. Respiratory Syncytial Virus Replication Is Promoted by Autophagy-Mediated Inhibition of Apoptosis. J Virol (2018) 92(8):e02193-17. doi: 10.1128/JVI.02193-17

178. Nakashima A, Tanaka N, Tamai K, Kyuuma M, Ishikawa Y, Sato H, et al. Survival of Parvovirus B19-Infected Cells by Cellular Autophagy. Virology (2006) 349:254-63. doi: 10.1016/j.virol.2006.03.029

179. Peng J, Zhu S, Hu L, Ye P, Wang Y, Tian Q, et al. Wild-Type Rabies Virus Induces Autophagy in Human and Mouse Neuroblastoma Cell Lines. Autophagy (2016) 12:1704-20. doi: 10.1080/15548627.2016.1196315

180. Meng G, Xia M, Wang D, Chen A, Wang Y, Wang H, et al. Mitophagy Promotes Replication of Oncolytic Newcastle Disease Virus by Blocking 
Intrinsic Apoptosis in Lung Cancer Cells. Oncotarget (2014) 5:6365-74. doi: 10.18632/oncotarget.2219

181. Noman MZ, Janji B, Kaminska B, Moer KV, Pierson S, Przanowski P, et al. Blocking Hypoxia-Induced Autophagy in Tumors Restores Cytotoxic T-Cell Activity and Promotes Regression. Cancer Res (2011) 71:5976-86. doi: 10.1158/0008-5472.CAN-11-1094

182. Viry E, Baginska J, Berchem G, Noman MZ, Medves S, Chouaib S, et al. Autophagic Degradation of GZMB/Granzyme B. Autophagy (2014) 10:1735. doi: 10.4161 /auto. 26924

183. Gong G, Waris G, Tanveer R, Siddiqui A. Human Hepatitis C Virus NS5A Protein Alters Intracellular Calcium Levels, Induces Oxidative Stress, and Activates STAT-3 and NF-kb. Proc Natl Acad Sci (2001) 98:9599-604. doi: $10.1073 /$ pnas. 171311298

184. Kenific CM, Thorburn A, Debnath J. Autophagy and Metastasis: Another Double-Edged Sword. Curr Opin Cell Biol (2010) 22:241-5. doi: 10.1016/ j.ceb.2009.10.008

185. Catalano M, D’Alessandro G, Lepore F, Corazzari M, Caldarola S, Valacca C, et al. Autophagy Induction Impairs Migration and Invasion by Reversing EMT in Glioblastoma Cells. Mol Oncol (2015) 9:1612-25. doi: 10.1016/ j.molonc.2015.04.016

186. Bell ES, Coelho PP, Ratcliffe CDH, Rajadurai CV, Peschard P, Vaillancourt R, et al. LC3C-Mediated Autophagy Selectively Regulates the Met RTK and HGF-Stimulated Migration and Invasion. Cell Rep (2019) 29:4053-4068.e6. doi: 10.1016/j.celrep.2019.11.063

187. Guadamillas MC, Cerezo A. Pozo MA Del. Overcoming Anoikis - Pathways to Anchorage-Independent Growth in Cancer. J Cell Sci (2011) 124:3189-97. doi: $10.1242 /$ jcs. 072165

188. Peng Y-F, Shi Y-H, Ding Z-B, Ke A-W, Gu C-Y, Hui B, et al. Autophagy Inhibition Suppresses Pulmonary Metastasis of HCC in mice via impairing anoikis resistance and colonization of HCC cells. Autophagy (2013) 9:205668. doi: 10.4161/auto. 26398

189. Sharif T, Martell E, Dai C, Kennedy BE, Murphy P, Clements DR, et al. Autophagic Homeostasis Is Required for the Pluripotency of Cancer Stem Cells. Autophagy (2017) 13:264-84. doi: 10.1080/15548627.2016.1260808

190. Mowers EE, Sharifi MN, Macleod KF. Autophagy in Cancer Metastasis. Oncogene (2017) 36:1619-30. doi: 10.1038/onc.2016.333

191. Ma L, Deng X, Wu M, Zhang G, Huang J. Down-Regulation of Mirna-204 by LMP-1 Enhances CDC42 Activity and Facilitates Invasion of EBVAssociated Nasopharyngeal Carcinoma Cells. FEBS Lett (2014) 588:156270. doi: 10.1016/j.febslet.2014.02.039

192. Cai L-M, Lyu X-M, Luo W-R, Cui X-F, Ye Y-F, Yuan C-C, et al. EBV-MiRBART7-3p Promotes the EMT and Metastasis of Nasopharyngeal Carcinoma Cells by Suppressing the Tumor Suppressor PTEN. Oncogene (2015) 34:2156-66. doi: 10.1038/onc.2014.341

193. Yan Q, Zeng Z, Gong Z, Zhang W, Li X, He B, et al. EBV-Mir-BART10-3p Facilitates Epithelial-Mesenchymal Transition and Promotes Metastasis of Nasopharyngeal Carcinoma by Targeting BTRC. Oncotarget (2015) 6:4176682. doi: 10.18632/oncotarget.6155

194. Li G, Wu Z, Peng Y, Liu X, Lu J, Wang L, et al. Microrna-10b Induced by Epstein-Barr Virus-Encoded Latent Membrane Protein-1 Promotes the Metastasis of Human Nasopharyngeal Carcinoma Cells. Cancer Lett (2010) 299:29-36. doi: 10.1016/j.canlet.2010.07.021

195. Zhu X, Wang Y, Sun Y, Zheng J, Zhu D. MiR-155 Up-Regulation by LMP1 DNA Contributes to Increased Nasopharyngeal Carcinoma Cell Proliferation and Migration. Eur Arch Otorhinolaryngol (2014) 271:193945. doi: 10.1007/s00405-013-2818-0

196. Wang Q, Song R, Zhao C, Liu H, Yang Y, Gu S, et al. HPV16 E6 Promotes Cervical Cancer Cell Migration and Invasion by Downregulation of NHERF1. Int J Cancer (2019) 144:1619-32. doi: 10.1002/ijc.31876

197. Mileo AM, Piombino E, Severino A, Tritarelli A, Paggi MG, Lombardi D. Multiple Interference of the Human Papillomavirus-16 E7 Oncoprotein With the Functional Role of the Metastasis Suppressor Nm23-H1 Protein. J Bioenerg Biomembr (2006) 38:215. doi: 10.1007/s10863-006-9037-y

198. Khera L, Paul C, Kaul R. Hepatitis C Virus E1 Protein Promotes Cell Migration and Invasion by Modulating Cellular Metastasis Suppressor Nm23-H1. Virology (2017) 506:110-20. doi: 10.1016/j.virol.2017.03.014

199. Wang X, Liu S, Zhou Z, Yan H, Xiao J. A Herpes Simplex Virus Type 2Encoded Microrna Promotes Tumor Cell Metastasis by Targeting
Suppressor of Cytokine Signaling 2 in Lung Cancer. Tumor Biol (2017) 39 (5):1010428317701633. doi: 10.1177/1010428317701633 1010428317701633.

200. Vomaske J, Varnum S, Melnychuk R, Smith P, Pasa-Tolic L, Shutthanandan JI, et al. HCMV Pus28 Initiates Pro-Migratory Signaling via Activation of Pyk2 Kinase. Herpesviridae (2010) 1:2. doi: 10.1186/2042-4280-1-2

201. Sheng Y, Li J, Zou C, Wang S, Cao Y, Zhang J, et al. Downregulation of Mir101-3p by Hepatitis B Virus Promotes Proliferation and Migration of Hepatocellular Carcinoma Cells by Targeting Rab5a. Arch Virol (2014) 159:2397-410. doi: 10.1007/s00705-014-2084-5

202. Belaid A, Cerezo M, Chargui A, Corcelle-Termeau E, Pedeutour F, Giuliano S, et al. Autophagy Plays a Critical Role in the Degradation of Active RHOA, the Control of Cell Cytokinesis and Genomic Stability. Cancer Res (2013) 73:4311-22. doi: 10.1158/0008-5472.CAN-12-4142

203. Zhang Y, Li J, Wang S, Yang F, Zhou Y, Liu Y, et al. Hbx-Associated Long Non-Coding RNA Activated by TGF- $\beta$ Promotes Cell Invasion and Migration by Inducing Autophagy in Primary Liver Cancer. Int J Oncol (2020) 56:337-47. doi: 10.3892/ijo.2019.4908

204. Bao L, Jaramillo MC, Zhang Z, Zheng Y, Yao M, Zhang DD, et al. Induction of Autophagy Contributes to Cisplatin Resistance in Human Ovarian Cancer Cells. Mol Med Rep (2015) 11:91-8. doi: 10.3892/mmr.2014.2671

205. Chen Z, Jiang Q, Zhu P, Chen Y, Xie X, Du Z, et al. NPRL2 Enhances Autophagy and the Resistance to Everolimus in Castration-Resistant Prostate Cancer. Prostate (2019) 79:44-53. doi: 10.1002/pros.23709

206. Sui X, Kong N, Wang X, Fang Y, Hu X, Xu Y, et al. JNK Confers 5Fluorouracil Resistance in P53-Deficient and Mutant P53-Expressing Colon Cancer Cells by Inducing Survival Autophagy. Sci Rep (2014) 4:4694. doi: 10.1038/srep04694

207. Wang J, Wu GS. Role of Autophagy in Cisplatin Resistance in Ovarian Cancer Cells. J Biol Chem (2014) 289:17163-73. doi: 10.1074/ jbc.M114.558288

208. Xiao X, Wang W, Li Y, Yang D, Li X, Shen C, et al. HSP90AA1-Mediated Autophagy Promotes Drug Resistance in Osteosarcoma. J Exp Clin Cancer Res (2018) 37:201. doi: 10.1186/s13046-018-0880-6

209. Chen X, Wang P, Guo F, Wang X, Wang J, Xu J, et al. Autophagy Enhanced the Radioresistance of Non-Small Cell Lung Cancer by Regulating ROS Level Under Hypoxia Condition. Int J Radiat Biol (2017) 93:764-70. doi: 10.1080/ 09553002.2017.1325025

210. Hu JL, He GY, Lan XL, Zeng ZC, Guan J, Ding Y, et al. Inhibition of ATG12Mediated Autophagy by Mir-214 Enhances Radiosensitivity in Colorectal Cancer. Oncogenesis (2018) 7:1-12. doi: 10.1038/s41389-018-0028-8

211. Lomonaco SL, Finniss S, Xiang C, DeCarvalho A, Umansky F, Kalkanis SN, et al. The Induction of Autophagy by $\gamma$-Radiation Contributes to the Radioresistance of Glioma Stem Cells. Int J Cancer (2009) 125:717-22. doi: $10.1002 /$ ijc.24402

212. Wang P, Zhang J, Zhang L, Zhu Z, Fan J, Chen L, et al. Microrna 23b Regulates Autophagy Associated With Radioresistance of Pancreatic Cancer Cells. Gastroenterology (2013) 145:1133-1143.e12. doi: 10.1053/.j.gastro.2013.07.048

213. Chen Y, Li X, Guo L, Wu X, He C, Zhang S, et al. Combining Radiation With Autophagy Inhibition Enhances Suppression of Tumor Growth and Angiogenesis in Esophageal Cancer. Mol Med Rep (2015) 12:1645-52. doi: $10.3892 / \mathrm{mmr} .2015 .3623$

214. Cheng CY, Liu JC, Wang JJ, Li YH, Pan J, Zhang YR. Autophagy Inhibition Increased the Anti-Tumor Effect of Cisplatin on Drug-Resistant Esophageal Cancer Cells. J Biol Regul Homeost Agents (2017) 31:645-52.

215. Ching RHH, Sze KMF, Lau EYT, Chiu Y-T, Lee JMF, Ng IOL. Lee TKW. CTerminal Truncated Hepatitis B Virus X Protein Regulates Tumorigenicity, Self-Renewal and Drug Resistance via STAT3/Nanog Signaling Pathway. Oncotarget (2017) 8:23507-16. doi: 10.18632/oncotarget.15183

216. Su K-J, Yu Y-L. Downregulation of SHIP2 by Hepatitis B Virus X Promotes the Metastasis and Chemoresistance of Hepatocellular Carcinoma Through SKP2. Cancers (2019) 11:1065. doi: 10.3390/cancers 11081065

217. Tan Y, Li Y. HCV Core Protein Promotes Hepatocyte Proliferation and Chemoresistance by Inhibiting NR4A1. Biochem Biophys Res Commun (2015) 466:592-8. doi: 10.1016/j.bbrc.2015.09.091

218. Wang C, Wang M, Cheng P, Huang H, Dong W, Zhang W, et al. Hepatitis B Virus X Protein Promotes the Stem-Like Properties of OV6 + Cancer Cells in Hepatocellular Carcinoma. Cell Death Dis (2018) 8:e2560-0. doi: 10.1038/ cddis. 2016.493 
219. Bourguignon LYW, Earle C, Shiina M. Hyaluronan-CD44 Interaction Promotes HPV 16 E6 Oncogene-Mediated Oropharyngeal Cell Carcinoma Survival and Chemoresistance. Matrix Biol (2019) 78-79:180-200. doi: 10.1016/j.matbio.2018.07.008

220. Jia Q, Yan C, Zheng X, Pan X, Cao X, Cao L. Upregulation of MTA1 Expression by Human Papillomavirus Infection Promotes CDDP Resistance in Cervical Cancer Cells via Modulation of NF-kb/APOBEC3B Cascade. Cancer Chemother Pharmacol (2019) 83:625-37. doi: 10.1007/s00280-01803766-2

221. Kim H, Choi H, Lee SK. Epstein-Barr Virus Mir-BART20-5p Regulates Cell Proliferation and Apoptosis by Targeting BAD. Cancer Lett (2015) 356:73342. doi: 10.1016/j.canlet.2014.10.023

222. Yang G-D, Huang T-J, Peng L-X, Yang C-F, Liu R-Y, Huang H-B, et al. Epstein-Barr Virus_Encoded LMP1 Upregulates Microrna-21 to Promote the Resistance of Nasopharyngeal Carcinoma Cells to Cisplatin-Induced Apoptosis by Suppressing PDCD4 and Fas-L. PloS One (2013) 8:e78355. doi: 10.1371/journal.pone.0078355

223. Seo JS, Kim T-G, Hong YS, Chen J-Y, Lee SK. Contribution of Epstein-Barr Virus Infection to Chemoresistance of Gastric Carcinoma Cells to 5Fluorouracil. Arch Pharm Res (2011) 34:635-43. doi: 10.1007/s12272-0110414-7

224. Wu Q, Han T, Sheng X, Zhang N, Wang P. Downregulation of EB Virus MirBART4 Inhibits Proliferation and Aggressiveness While Promoting Radiosensitivity of Nasopharyngeal Carcinoma. BioMed Pharmacother (2018) 108:741-51. doi: 10.1016/j.biopha.2018.08.146

225. Zhou X, Zheng J, Tang Y, lin Y, Wang L, Li Y, et al. EBV Encoded miRNA BART8-3p Promotes Radioresistance in Nasopharyngeal Carcinoma by Regulating ATM/ATR Signaling Pathway. Biosci Rep (2019) 39(9): BSR20190415. doi: 10.1042/BSR20190415

226. Lu J, Tang M, Li H, Xu Z, Weng X, Li J, et al. EBV-LMP1 Suppresses the DNA Damage Response Through DNA-PK/AMPK Signaling to Promote Radioresistance in Nasopharyngeal Carcinoma. Cancer Lett (2016) 380:191200. doi: 10.1016/j.canlet.2016.05.032

227. Xu S, Zhou Z, Peng X, Tao X, Zhou P, Zhang K, et al. EBV-LMP1 Promotes Radioresistance by Inducing Protective Autophagy Through BNIP3 in Nasopharyngeal Carcinoma. Cell Death Dis (2021) 12:1-12. doi: 10.1038/ s41419-021-03639-2

228. Antonioli M, Pagni B, Vescovo T, Ellis R, Cosway B, Rollo F, et al. HPV Sensitizes OPSCC Cells to Cisplatin-Induced Apoptosis by Inhibiting Autophagy Through E7-Mediated Degradation of AMBRA1. Autophagy (2020) 11:1-14. doi: 10.1080/15548627.2020.1847444

229. Boukhaled GM, Harding S, Brooks DG. Opposing Roles of Type I Interferons in Cancer Immunity. Annu Rev Pathol (2021) 16:167-98. doi: 10.1146/annurev-pathol-031920-093932

230. Tal MC, Sasai M, Lee HK, Yordy B, Shadel GS, Iwasaki A. Absence of Autophagy Results in Reactive Oxygen Species-Dependent Amplification of RLR Signaling. Proc Natl Acad Sci (2009) 106(8):2770-5. doi: 10.1073/ pnas.0807694106

231. Shi C-S, Qi H-Y, Boularan C, Huang N-N, Abu-Asab M, Shelhamer JH, et al. SARS-Coronavirus Open Reading Frame-9b Suppresses Innate Immunity by Targeting Mitochondria and the MAVS/TRAF3/TRAF6 Signalosome. J Immunol (2014) 193(6):3080-9. doi: 10.4049/jimmunol.1303196

232. Ding B, Zhang L, Li Z, Zhong Y, Tang Q, Qin Y, et al. The Matrix Protein of Human Parainfluenza Virus Type 3 Induces Mitophagy That Suppresses Interferon Responses. Cell Host Microbe (2017) 21:538-547.e4. doi: 10.1016/ j.chom.2017.03.004

233. Xia M, Gonzalez P, Li C, Meng G, Jiang A, Wang H, et al. Mitophagy Enhances Oncolytic Measles Virus Replication by Mitigating DDX58/ RIG-I-Like Receptor Signaling. J Virol (2014) 88:5152-64. doi: 10.1128/ JVI.03851-13

234. Wang R, Zhu Y, Ren C, Yang S, Tian S, Chen H, et al. Influenza a Virus Protein PB1-F2 Impairs Innate Immunity by Inducing Mitophagy. Autophagy (2021) 17:496-511. doi: 10.1080/15548627.2020.1725375
235. Yu J-W, Lee M-S. Mitochondria and the NLRP3 Inflammasome: Physiological and Pathological Relevance. Arch Pharm Res (2016) 39:1503-18. doi: 10.1007/s12272-016-0827-4

236. Zhou R, Yazdi AS, Menu P, Tschopp J. A Role for Mitochondria in NLRP3 Inflammasome Activation. Nature (2011) 469:221-5. doi: 10.1038/ nature 09663

237. Lupfer C, Thomas PG, Anand PK, Vogel P, Milasta S, Martinez J, et al. Receptor Interacting Protein Kinase 2-Mediated Mitophagy Regulates Inflammasome Activation During Virus Infection. Nat Immunol (2013) 14:480-8. doi: 10.1038/ni.2563

238. Komune N, Ichinohe T, Ito M, Yanagi Y. Measles Virus V Protein Inhibits Nlrp3 Inflammasome-Mediated Interleukin-1 $\beta$ Secretion(2011) (Accessed June 3, 2021). undefined.

239. Luo X, Donnelly CR, Gong W, Heath BR, Hao Y, Donnelly LA, et al. HPV16 Drives Cancer Immune Escape via NLRX1-Mediated Degradation of STING. J Clin Invest (2020) 130:1635-52. doi: 10.1172/JCI129497

240. Avia M, Rojas JM, Miorin L, Pascual E, Van Rijn PA, Martín V, et al. VirusInduced Autophagic Degradation of STAT2 as a Mechanism for Interferon Signaling Blockade. EMBO Rep (2019) 20:e48766. doi: 10.15252/ embr.201948766

241. Shiode Y, Hikita H, Tanaka S, Shirai K, Doi A, Sakane S, et al. Hepatitis C Virus Enhances Rubicon Expression, Leading to Autophagy Inhibition and Intracellular Innate Immune Activation. Sci Rep (2020) 10:15290. doi: 10.1038/s41598-020-72294-y

242. Muscolino E, Schmitz R, Loroch S, Caragliano E, Schneider C, Rizzato M, et al. Herpesviruses Induce Aggregation and Selective Autophagy of Host Signalling Proteins NEMO and RIPK1 as an Immune-Evasion Mechanism. Nat Microbiol (2020) 5:331-42. doi: 10.1038/s41564-019-0624-1

243. Fliss PM, Jowers TP, Brinkmann MM, Holstermann B, Mack C, Dickinson P, et al. Viral Mediated Redirection of NEMO/Ikk $\gamma$ to Autophagosomes Curtails the Inflammatory Cascade. PloS Pathog (2012) 8:e1002517. doi: 10.1371/journal.ppat.1002517

244. Hansen TH, Bouvier M. MHC Class I Antigen Presentation: Learning From Viral Evasion Strategies. Nat Rev Immunol (2009) 9:503-13. doi: 10.1038/ nri2575

245. Morrow G, Slobedman B, Cunningham AL, Abendroth A. Varicella-Zoster Virus Productively Infects Mature Dendritic Cells and Alters Their Immune Function. J Virol (2003) 77:4950-9. doi: 10.1128/jvi.77.8.4950-4959.2003

246. Loi M, Müller A, Steinbach K, Niven J, Barreira da Silva R, Paul P, et al. Macroautophagy Proteins Control MHC Class I Levels on Dendritic Cells and Shape Anti-Viral CD8(+) T Cell Responses. Cell Rep (2016) 15:1076-87. doi: 10.1016/j.celrep.2016.04.002

247. Yamamoto K, Venida A, Yano J, Biancur DE, Kakiuchi M, Gupta S, et al. Autophagy Promotes Immune Evasion of Pancreatic Cancer by Degrading MHC-I. Nature (2020) 581:100-5. doi: 10.1038/s41586-020-2229-5

Conflict of Interest: The authors declare that the research was conducted in the absence of any commercial or financial relationships that could be construed as a potential conflict of interest.

Publisher's Note: All claims expressed in this article are solely those of the authors and do not necessarily represent those of their affiliated organizations, or those of the publisher, the editors and the reviewers. Any product that may be evaluated in this article, or claim that may be made by its manufacturer, is not guaranteed or endorsed by the publisher.

Copyright (c) 2021 Leonardi, Sibéril, Alifano, Cremer and Joubert. This is an openaccess article distributed under the terms of the Creative Commons Attribution License (CC BY). The use, distribution or reproduction in other forums is permitted, provided the original author(s) and the copyright owner(s) are credited and that the original publication in this journal is cited, in accordance with accepted academic practice. No use, distribution or reproduction is permitted which does not comply with these terms. 